Produto \& Produção, vol. 14 n.2, p. 01-25, jun. 2013

RECEBIDO EM 23/05/2011. ACEITO EM 14/05/2013.

\title{
Aplicação de Seis Sigma em uma empresa de pequeno porte
}

\section{Carla Cristina Amodio Estorilio}

Universidade Tecnológica Federal do Paraná UTFPR

amodio@utfpr.edu.br

\section{Fernanda Gonçalves Amitrano}

Universidade Tecnológica Federal do Paraná UTFPR

feamitrano@gmail.com

\section{RESUMO}

O Seis Sigma vem sendo utilizado por grandes empresas para melhorar o desempenho de seus processos fabris. Entretanto, o interesse e a aplicação desta metodologia em pequenas e médias empresas é algo emergente, apesar de ser pouco difundido na literatura. Esse artigo mostra a aplicabilidade do Seis Sigma em uma pequena empresa brasileira, explicitando a estratégia de aplicação e seus impactos. O trabalho apresenta uma revisão sobre o Seis Sigma e o método DMAIC (Definir, Medir, Analisar, Melhorar e Controlar), utilizado com sucesso pelas indústrias e adequado para este caso, e aborda as particularidades da pequena empresa que poderiam influenciar nesta aplicação. Em seguida, detalha a aplicação do Seis Sigma com o DMAIC em uma pequena empresa de tratamento superficial de peças mecânicas. $\mathrm{O}$ artigo mostra a viabilidade, aplicabilidade e o impacto do Seis Sigma nesta pequena empresa, a qual obteve uma redução de retrabalho de aproximadamente $20 \%$ em seu processo de zincagem.

Palavras-chave: Seis Sigma, DMAIC, Empresa de Pequeno Porte

\section{ABSTRACT}

Six Sigma has been used by large companies to improve the performance of their manufacturing processes. However, the interest and the application of this methodology in small and medium-sized enterprises is something emerging, despite being little widespread in the literature. This article shows the applicability of Six Sigma in a small Brazilian company, explaining the application strategy and its impacts. The work presents a review about Six Sigma and DMAIC method (define, measure, Analyze, Improve, and control), which had been mostly successful so far in large-scale industries and is suitable for this case, and shows the particularities of small business that could have some impact in this application. Then, details the application of Six Sigma with DMAIC in a small enterprise of superficial treatment of mechanical components. The article shows the feasibility, applicability, and impact of Six Sigma in this small company, which obtained a rework reduction of approximately $20 \%$ on their galvanizing process.

Key words: Six Sigma, DMAIC, small enterprise.

\section{Introdução}

O mercado de oferta e demanda é crescente e as oportunidades de negócios são inúmeras e atrativas (TONINI et al., 2008). Porém, os consumidores possuem preferência por produtos cada vez me- 
lhores que atendam ou superem as suas expectativas, com preços acessíveis (MACHADO, 2006). Nesse sentido, as empresas precisam ganhar velocidade, flexibilidade e precisão por meio de recursos que contribuam com o desenvolvimento de produtos eficazes (VIEIRA; ALMEIDA, 2008).

Em busca desse alto desempenho, a metodologia Seis Sigma vem se disseminando de forma crescente entre as grandes empresas, notadamente as multinacionais. O Seis Sigma é uma metodologia que combina métodos estatísticos e da qualidade, visando reduzir defeitos e variações no projeto, promovendo um aumento na qualidade dos produtos resultantes desse processo. Porém, entre as micro, pequenas e médias empresas (MPMEs), a difusão desta metodologia parece ainda representar um desafio, a julgar pela pouca evidência documentada da implementação do Seis Sigma em pequenas organizações (KURATKO; GOODALE; HORNSBY, 2001; ANTONY; KUMAR; MADU, 2005), em especial nas empresas brasileiras (DUARTE; RAMOS, 2006). Apesar de haverem muitas publicações sobre o Seis Sigma, a maioria se refere às empresas de grande porte (ANDRIETTA; MIGUEL, 2007). Podem-se citar, como exemplo, os estudos de Cleto e Quinteiro (2011), Santos e Martins (2010), Carvalho et al. (2007), Ruthes et al. (2006), Ariente et al. (2005) e Andrietta e Miguel (2002). Harry e Crawford (2004) afirmam que o Seis Sigma, originalmente, não foi projetado para as MPMEs.

Recentemente, Rodrigues e Werne (2012) fizeram uma pesquisa para identificar como ocorria o programa Seis Sigma em onze empresas localizadas no Rio grande do Sul (Brasil) e concluíram que 91\% dessas empresas eram de grande porte, sendo a maioria dos Setores automotivo e agrícola.

Dentre as publicações existentes no Brasil, que abordam o Seis Sigma em empresas de pequeno porte, pode-se citar Magalhães e Figueiredo (2007), que identifica os fatores críticos enfrentados por quatro empresas de pequeno e médio porte que aplicam o Seis Sigma.

Outro estudo foi realizado por Duarte e Ramos (2006), que através de um survey, buscou conhecer os fatores que influenciavam na decisão de adoção ou não do Seis Sigma por parte das MPMEs de autopeças. O estudo conclui que os fatores de influência são: a conscientização da Direção, a competência preexistente para condução de projetos, o volume de recursos disponíveis e a preexistência de uma cultura da qualidade. Porém, nenhum desses estudos mostra os procedimentos envolvidos na aplicação prática do Seis Sigma em MPMEs, que possa ser replicado por empresários sem a contratação de agentes externos.

Para que o Seis Sigma possa ser aplicado pelas MPMEs é necessário que a metodologia tradicional seja adaptada, para torná-lo "sustentável". Diversos autores como Munro (2000), Wessel e Burcher (2004), Antony, Kumar e Madu (2005), Antony (2008) e Harry e Crawford (2004) fazem sugestões para facilitar a implantação do Seis Sigma em MPMEs, porém, acreditam que o principal fator inibidor é o custo excessivo da seleção e preparação da equipe. As MPMEs teriam dificuldades em treinar e dispor de seus poucos funcionários melhor qualificados, responsáveis por múltiplas funções, para atuar em equipes de melhoria, e depois ter que esperar meses para o retorno deste investimento.

Quanto a estudo de caso aplicado de Seis Sigma em MPMEs, em especial na pequena empresa, identificou-se o de Kaushik et al. (2012), o qual apresenta uma aplicação em uma empresa indiana, fabricante de bicicletas, que poderia ser adaptado para outras empresas de pequeno porte, porem, não foram encontrados artigos relatando casos práticos aplicados em pequenas empresas brasileiras.

Sendo assim, esse estudo tem por objetivo mostrar uma aplicação do Seis Sigma em uma empresa brasileira de pequeno porte, detalhando a estratégia utilizada através de uma demonstração em ambiente industrial, sem consultoria externa especializada, explicitando os impactos desencadeados em curto prazo.

Para isso, os conceitos da metodologia Seis Sigma e as particularidades das empresas de pequeno porte são apresentados, incluindo o método DMAIC (Define, Measure, Analyze, Improve, and Control - Definir, Medir, Analisar, Melhorar e Controlar), escolhido como estratégia de aplicação. Um ambiente industrial é delimitado para a aplicação do Seis Sigma, no qual as etapas do DMAIC são aplicadas de forma simples, incluindo métodos como o FMEA de processo (Análise dos Efeitos e Modos de Falhas), DOE (Design of Experiments - Projeto de Experimentos) e outros. Visando medir os impactos da aplicação do Seis Sigma, alguns indicadores de desempenho são monitorados antes e depois da aplicação do Seis Sigma, explicitando quantitativamente os benefícios alcançados. 


\section{Metodologia}

Inicialmente foi realizada uma revisão bibliográfica sobre os temas: Seis Sigma e sua estratégia de aplicação DMAIC, além de abordar as características das empresas de pequeno porte, que impactam no processo de aplicação do Seis Sigma. Posteriormente, é apresentada a aplicação do Seis Sigma, com o método DMAIC, em uma pequena empresa de tratamento superficial, sendo o processo de zincagem delimitado para o estudo por apresentar altos índices de retrabalho.

Considerando as particularidades das empresas de pequeno porte e o tempo disponível para a aplicação do Seis Sigma, apenas alguns métodos recomendáveis na literatura de Seis Sigma- DMAIC foram aplicados nesse caso prático industrial. Esses foram delimitados baseando-se em Satolo et al. (2009), que afirma serem esses métodos os mais utilizados, de comprovada eficácia e de menor custo de aplicação. A Figura 1 apresenta esses métodos, assim como, as fases do DMAIC nas quais eles são aplicados, incluindo as demais etapas metodológicas que compõem esse trabalho. Detalhes sobre o DMAIC e os recursos aplicados são abordados na revisão bibliográfica, apresentada no próximo item.

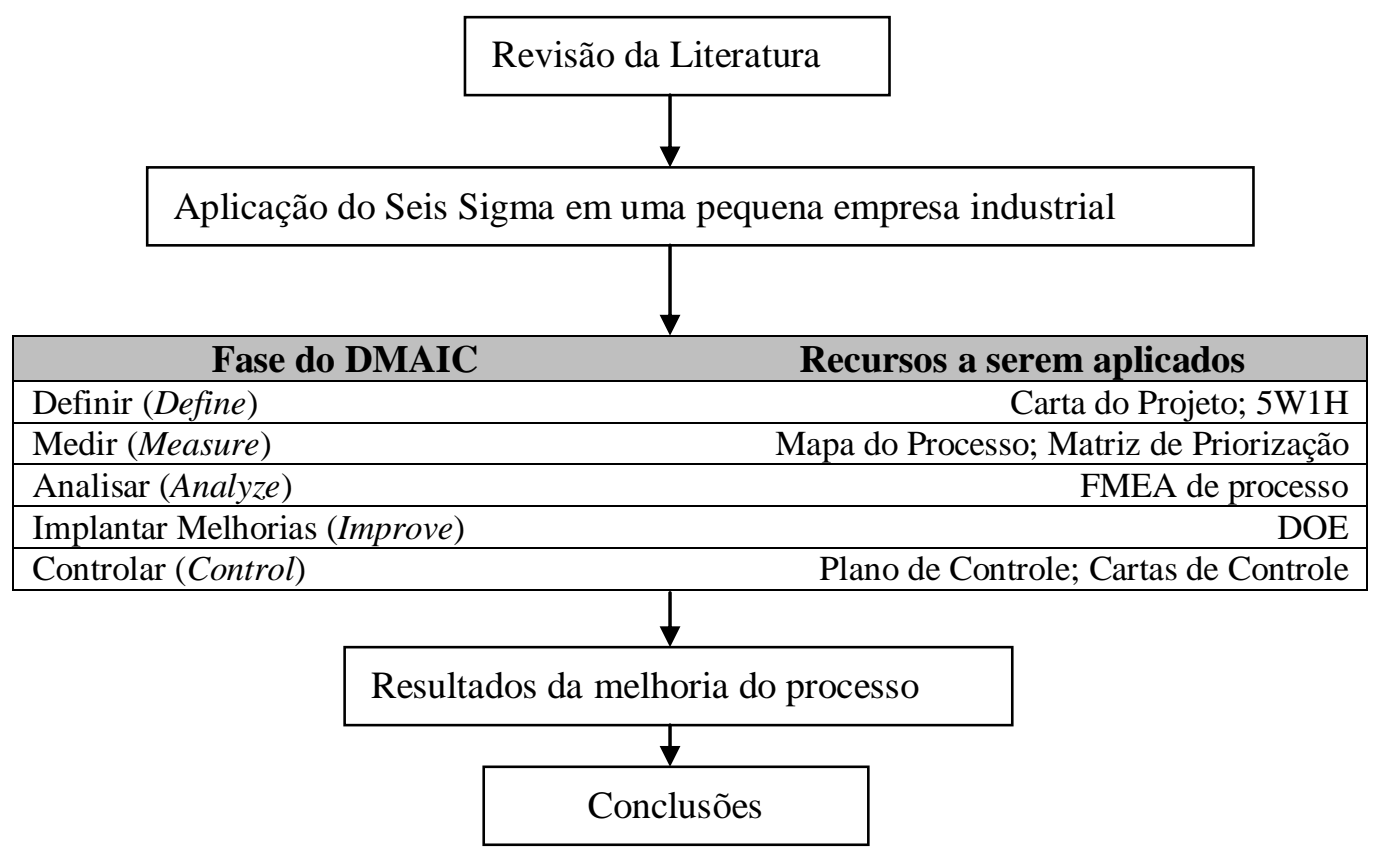

Figura 1 - Fluxo metodológico utilizado no trabalho (Fonte: Elaborada pelas Autoras).

\section{O Seis Sigma e a pequena empresa}

O programa Seis Sigma representa o programa de gestão da qualidade mais recente, tendo surgido na empresa norte-americana Motorola em 1987, com o objetivo de melhorar o desempenho da empresa através de estudos focados na variabilidade dos processos de produção (HENDERSON; EVANS, 2000). Ele está embasado em diversas características de modelos anteriores, como o pensamento estatístico, típico da época de maior ênfase no controle da qualidade, e a análise e solução de problemas (BOARIN et al., 2009). O Seis Sigma apresenta uma preocupação com o uso sistemático das ferramentas estatísticas, seguindo um ciclo batizado de DMAIC, o qual será detalhado posteriormente (CARVALHO; PALADINI, 2005; PYZDEK, 2003).

Apesar de a Motorola ser a precursora do Seis Sigma, a metodologia ganhou popularidade em 1994, quando o presidente da GE (General Electric) considerou-a o caminho para a busca da qualidade superior e da rentabilidade (WELCH, 2001).

$\mathrm{Na}$ literatura, é possível encontrar diferentes abordagens quanto à definição do Seis Sigma. Uma delas define Seis Sigma como um conjunto de ferramentas estatísticas associadas à gestão da qualidade, com o objetivo de definir um planejamento estruturado para a melhoria de um processo (TJAHJONO et al.,2010). 
A nomenclatura tem origem na própria estatística, onde a letra grega "Sigma" $(\sigma)$ representa a medida da variação do processo fabril, também conhecida como desvio padrão do valor almejado (KLEFSJO et al., 2001). Estatisticamente, "Seis Sigma" significa que, em uma distribuição normal centralizada, podem ser encontrados seis desvios padrões entre a média e o limite inferior de especificação (LIE) e mais seis desvios padrões entre a média e o limite superior de especificação (LSE), resultando em 1,2 defeitos por bilhão de oportunidades (DPBO). A Figura 2 mostra o gráfico desse tipo de distribuição normal centralizada e os níveis Sigma entre a média e os limites de especificação, a qual pode ser referente à dimensão de uma peça mecânica, por exemplo.

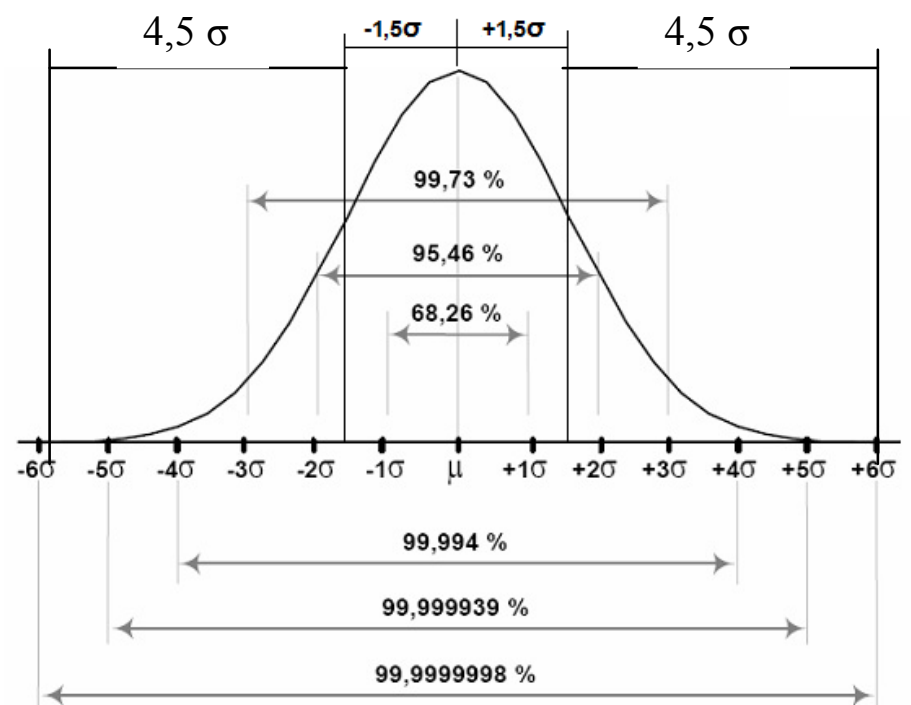

Figura 2 - Gráfico de distribuição normal centralizada (TENNANT, 2002).

Rotondaro et al. (2002) afirmam que, a longo prazo, é difícil manter um processo centralizado, conforme pressupõe a distribuição normal. Por essa razão, convencionou-se o deslocamento a partir da média nominal de 1,5 desvios padrões. Sendo assim, um processo pode ser considerado Seis Sigma ao atingir 4,5 desvios padrões entre a média e o limite inferior de especificação e 4,5 desvios padrões entre a média e o limite superior de especificação. Dessa forma, como pode ser visto na Figura 2, quando a curva aproxima-se do 4,5 $\sigma$ na esquerda e na direita, os defeitos praticamente se estabilizam e se aproximam a zero, atingindo um alto grau de qualidade.

A Tabela 1 relaciona o nível Sigma com o índice DPMO (Defeitos por Milhão de Oportunidades), mostrando o impacto nos custos pela baixa qualidade em cada nível.

Tabela 1 - Escala da qualidade. (Adaptado de Einset e Marzano (2002))

\begin{tabular}{|c|c|c|}
\hline Nível Sigma & $\begin{array}{c}\text { Máx. de defeitos por Milhão } \\
\text { (DPMO) }\end{array}$ & Custo da baixa qualidade (\% Vendas) \\
\hline 6 Sigma & 3,4 & $<5$ \\
\hline 5 Sigma & 233 & 5 a 10 \\
\hline 4 Sigma & 6.210 & 10 a 15 \\
\hline 3 Sigma & $\mathbf{6 6 . 8 0 7}$ & $\mathbf{1 5} \mathbf{~ 2 0}$ \\
\hline 2 Sigma & 308.537 & 20 a 25 \\
\hline 1 Sigma & 691.462 & $>25$ \\
\hline
\end{tabular}

De acordo com Einset e Marzano (2002), o significado dos valores explicitados na Tabela 1 indica que a média das indústrias opera em um nível de qualidade 3 Sigma e que isso custa entre 15\% e $20 \%$ de seu faturamento em desperdícios com retrabalho, inspeções, testes e outras perdas. 
Para calcular o índice DPMO se utiliza a razão entre o número de peças reprovadas e o número de peças produzidas, multiplicada por um milhão. Por exemplo; se foi produzido 100 peças e 5 foram reprovadas, considera-se " 5 divididos por 100 " e multiplica-se esse resultado por um milhão, resultando em 50 mil DPMO, o que se enquadra em um processo 3 Sigma. Essa abordagem é utilizada em processos medidos por atributos, ou seja, peças conformes ou não conformes.

Para aplicar o Seis Sigma, visando alcançar altos níveis de qualidade ou redução de defeitos por milhão, é preciso definir uma estratégia adequada para a sua aplicação. Conforme Pinto et al. (2006), $100 \%$ das empresas que aplicam o Seis Sigma utilizam o DMAIC em alguns de seus processos de fabricação, por serem processos já existentes. Rodrigues e Werne (2012), em uma pesquisa sobre Seis Sigma com onze empresas gaúchas, constataram que o método de aplicação mais utilizado era o DMAIC. No caso de novos processos, recomenda-se a utilização do DFSS (Design for Six Sigma), que atinge no máximo 39,1\% dos casos encontrados nas empresas. Segundo Mast e Lokkerbol (2012), apesar da sua popularidade, o DMAIC não é o mais indicado quando o escopo do problema é simples e restrito. Ou seja, ele é recomendado para processos existentes que apresentam situações complexas, envolvendo mais de duas variáveis durante a sua operação. Considerando que o presente trabalho se concentra na melhoria de um processo de fabricação já consolidado, o qual envolve mais de duas variáveis durante a sua execução, apenas o método DMAIC será apresentado.

\subsection{Método DMAIC}

O método DMAIC começou a ser difundido com o Seis Sigma, ou seja, pela Motorola na década de 80, popularizado pela GE com o Programa Seis Sigma, que forma especialistas empenhados em atacar problemas de maneira organizada, com o apoio de ferramentas da qualidade e da estatística, com certo grau de complexidade. Ele é aplicado em cinco fases, relacionadas ao seu próprio nome. São elas: Definir, Medir, Analisar, Melhorar e Controlar. Essas fases garantem que as empresas apliquem o Seis Sigma de forma metódica e disciplinada (ANDRIETTA; MIGUEL, 2007). Em relação aos recursos envolvidos nesse procedimento de melhoria de processo com o Seis Sigma, de acordo com a pesquisa realizada por Rodrigues e Werne (2012), as mais utilizadas são: FMEA, Mapas de Processo, Diagrama de Causa e Efeito, Gráfico de Pareto e Cartas de Controle. Porém, existem outros que podem contribuir com esse tipo de procedimento, os quais devem ser utilizados conforme a necessidade do projeto em questão.

\subsubsection{Fase definir}

Na primeira fase do DMAIC se define qual processo de fabricação será escolhido para a aplicação do Seis Sigma. Segundo Rotandaro et al. (2002), definir a Equipe Seis Sigma logo no início é fundamental para o sucesso da aplicação, pois toda a metodologia é desenvolvida por pessoas. A equipe de trabalho deve apresentar a seguinte estrutura:

a. Núcleo Base - composto pelas pessoas especialistas em Seis Sigma, responsáveis pelo projeto desde seu planejamento até a sua execução;

b. Membros - pessoas que integrarão a equipe durante determinadas fases do projeto;

c. Especialistas - pessoas com conhecimentos especializados dos processos que compõem as áreas contempladas pelo projeto, com a finalidade de prestar serviço à equipe do projeto.

As denominações dos papéis a serem desempenhados na equipe varia em função da carga horária de treinamento, hierarquia nos projetos e dedicação ao programa (ANDRIETTA; MIGUEL, 2007). Eles são denominados como: Sponsors, Champions, Master Black Belts (MBBs), Black Belts (BBs), Green Belts $(G B s)$, Yellows Belts (YBs) e White belts (WBs), cujos últimos cinco termos são oriundos da Unisys Corporation, baseando-se na arte marcial (karatê) (Boer et al., 2007). Segundo Pande et al., (2003) e Andrietta e Miguel (2007), eles possuem as seguintes atribuições:

- Sponsors - estão no topo da equipe e têm a responsabilidade de promover e definir as diretrizes para a implantação do Seis Sigma;

- Champions - membros da comissão executiva, os quais facilitam a obtenção de recursos e a eliminação de barreiras no desenvolvimento de projetos de melhoria; 
- Master Black Belts - fazem a ligação entre a gestão geral do projeto Seis Sigma e as pessoas responsáveis por cada um dos projetos de melhoria;

- Black Belts - lideram projetos específicos. Trabalham com funções ligadas à identificação de novos projetos e no treinamento de GBs. Têm formação em métodos estatísticos, processo de melhoria da qualidade, entre outros;

- Green Belts - dedicam-se às melhorias, com tempo parcial dentro do projeto;

- Yellows Belts e White belts - compõem o chamado "chão-de-fábrica", porém são treinados para utilizar as ferramentas básicas do Seis Sigma que se aplicam às várias fases dos projetos.

Pande et al. (2001) propõem uma equipe estruturada, conforme apresentado na Quadro 1, onde são mostradas as funções básicas de cada cargo, incluindo os títulos utilizados dentro de um projeto Seis Sigma.

Quadro 1 - Equipe Seis Sigma (Adaptado de Pande et al. (2001))

\begin{tabular}{|c|c|c|}
\hline Papel Genérico & Função & Títulos dentro da Equipe $6 \sigma$ \\
\hline Conselho de Liderança & Alta Gerência da Empresa & $\begin{array}{l}\text { Conselho de Q, Comitê Geren- } \\
\text { cial da Empresa }\end{array}$ \\
\hline Patrocinador & Supervisionar do Projeto & Proprietário do Processo fabril \\
\hline Líder de Implantação & Apoiar o Grupo de Liderança & $\begin{array}{l}\text { Diretor } 6 \sigma \text {, Líder da Q, Master } \\
\text { Black Belt }\end{array}$ \\
\hline Coach (Treinador) & Consultor que dará suporte à equipe & Master Black Belt, Black Belt \\
\hline Líder da Equipe/Projeto & $\begin{array}{l}\text { Responsável pelo projeto } 6 \sigma \text { e por selecionar os } \\
\text { membros da equipe, definir técnicas utilizadas, } \\
\text { documentar resultados e histórico do projeto. }\end{array}$ & Black Belt, Green Belt \\
\hline Membro da Equipe & $\begin{array}{l}\text { Colaboradores que auxiliam a medição e análise } \\
\text { do processo }\end{array}$ & Green Belt, Membro da Equipe \\
\hline $\begin{array}{l}\text { Proprietário do } \\
\text { Processo }\end{array}$ & $\begin{array}{l}\text { Colaborador responsável por manter as melhori- } \\
\text { as após o Seis Sigma }\end{array}$ & Champion, Green Belt \\
\hline
\end{tabular}

Após a estruturação da equipe, devem-se levantar as necessidades dos clientes e determinar os processos críticos (relacionados ao baixo desempenho). Esta deve ser concluída através da elaboração de uma proposta de projeto a ser aprovada pela alta gerência.

A proposta de projeto, também chamada "Carta de Projeto", que segundo Pande et al. (2001), é o principal resultado da primeira etapa e deve conter a declaração do problema a ser resolvido, as metas a serem alcançadas, as diretrizes da equipe Seis Sigma, a relação dos membros da equipe e as datas do cronograma a serem cumpridas. Nessa fase a equipe também determina a "missão do projeto" através da técnica " $5 \mathrm{~W} 1 \mathrm{H}$ " (Who, What, Why, Where, When, How), a qual consiste em responder as seguintes perguntas relacionadas ao projeto em questão: "Quem?", "O que?", "Por quê?", "Onde?", "Quando?" e "Como?".

\subsubsection{Fase medir}

Essa fase visa determinar a situação no início da implantação do Seis Sigma e as potenciais fontes de variação do processo fabril. Para identificar os processos críticos, segundo Rotondaro et al. (2002), é necessário modelar o processo foco e os subprocessos a ele associados, definindo as entradas e saídas de cada fase, estabelecendo as relações entre elas e classificando as entradas como características controladas ou não controladas Para isso, a técnica mais utilizada é o Mapa do Processo. Esse deve ser preenchido através da contribuição de todos os membros da equipe Seis Sigma, além de utilizar documentações existentes na empresa e contar com a experiência dos colaboradores em todos os níveis hierárquicos e, em alguns casos, com a experiência dos clientes e fornecedores. Um modelo de mapa do processo proposto por Rath e Strong (2001) é mostrado na Figura 3: 


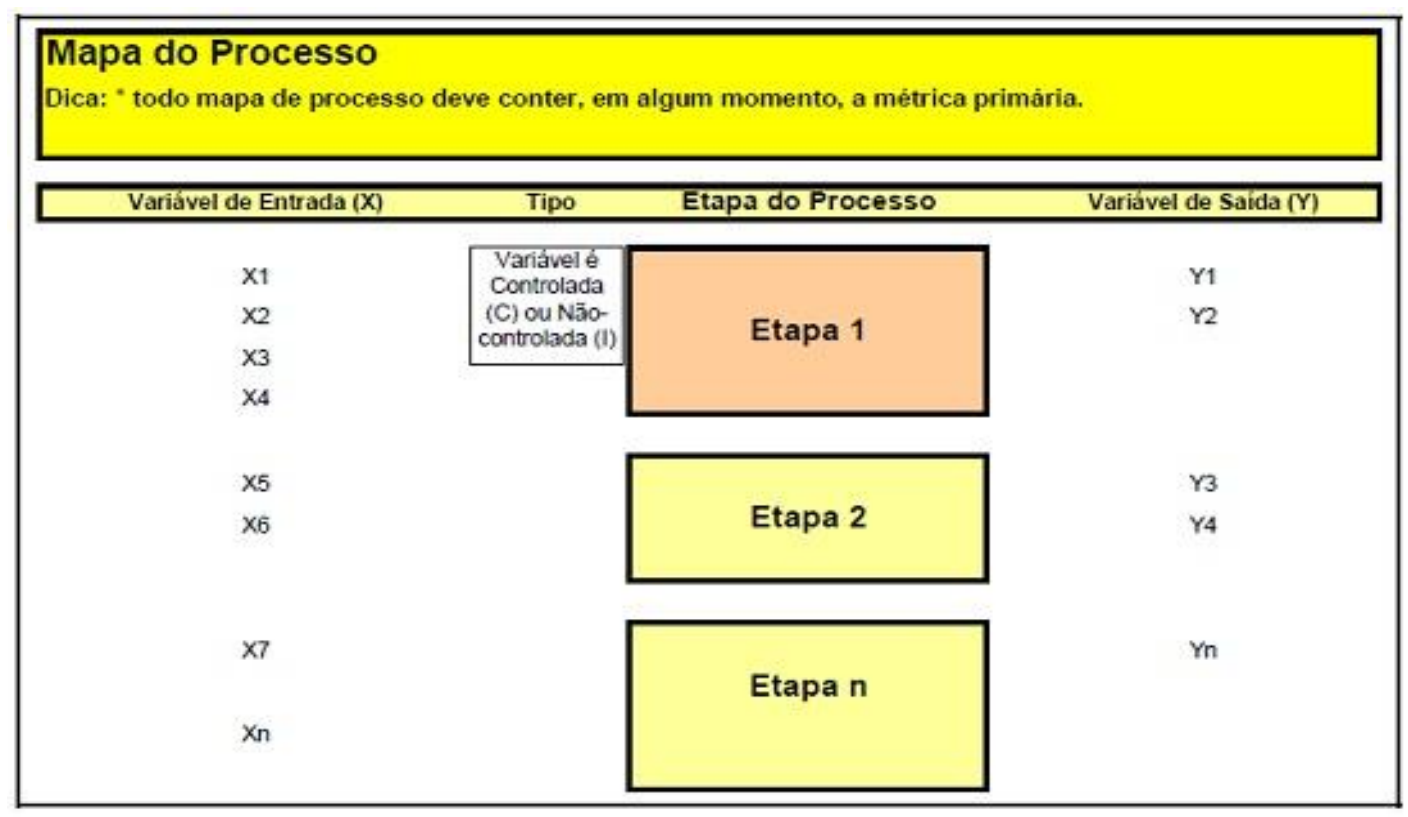

Figura 3 - Modelo de Mapa do Processo (RATH; STRONG, 2001)

Com o objetivo de estabelecer as relações entre as entradas X e as saídas Y, mostradas na Figura 3, tem-se a Matriz de Priorização, apresentada na Figura 4, que utiliza o Mapa do Processo como principal fonte de informação. O preenchimento dessa Matriz inicia com a correlação das variáveis de entrada do processo na segunda coluna e as principais variáveis de saída na segunda linha. Para cada variável de saída deve ser atribuída uma taxa de importância de 1 a 10, segundo critérios a serem estabelecidos pela equipe. Em seguida, a equipe estabelece um valor de correlação entre cada variável de entrada e de saída, de tal forma que os valores baixos implicam em pequena influência da variável de entrada na variável de saída e os valores altos implicam em grande influência.

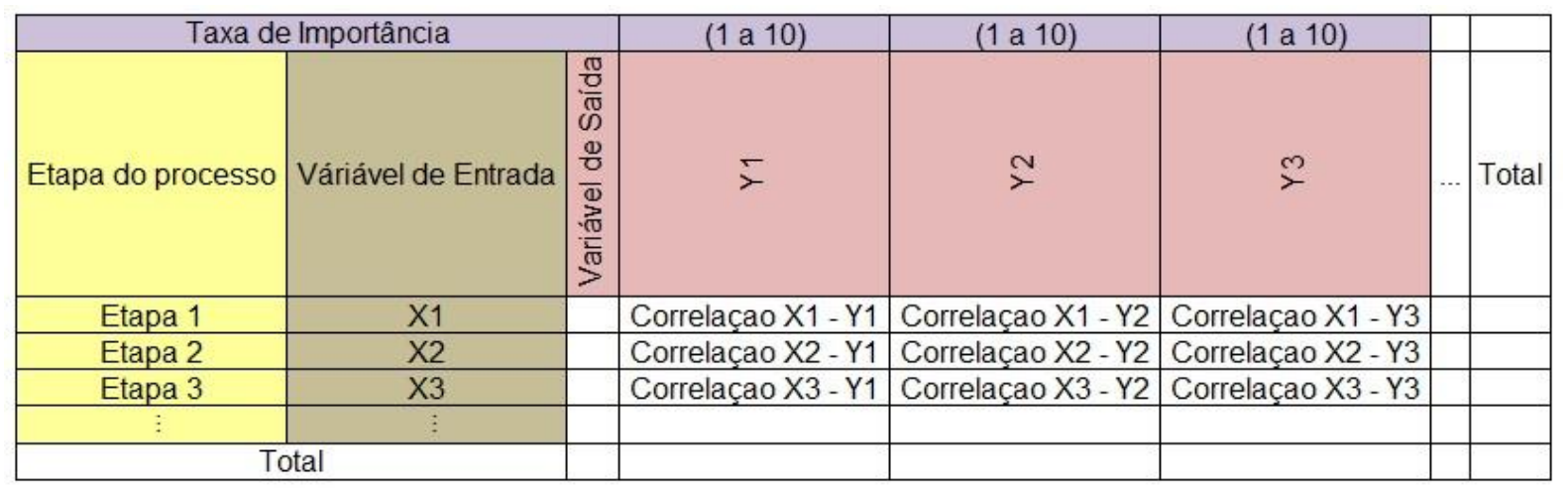

Figura 4 - Exemplo de preenchimento de uma Matriz de Priorização (Elaborada pelas autoras).

O cálculo do valor total para cada variável de entrada, explicitado na última coluna, é realizado através da soma das multiplicações entre os valores de correlação e as taxas de importância, conforme mostra a Equação 1.

$$
\text { ValorTotal }=\sum_{i=0}^{n} C_{j i} \times T_{i} \quad \text { Equação 1 }
$$

Onde:

$$
\begin{aligned}
& \text { J - índice da variável de entrada } \\
& \text { i - índice da variável de saída } \\
& \text { C - taxa de correlação } \\
& \text { T - taxa de importância }
\end{aligned}
$$


A Figura 5 apresenta um exemplo de cálculo do valor total das correlações, simulando a análise de um processo de jateamento. Para a análise dos resultados, considera-se que quanto maior o valor total, maior a influência da variável de entrada na qualidade do produto final. Nesse caso, adotou-se uma escala de 0 a 5 para as correlações entre as variáveis de entrada e saída.

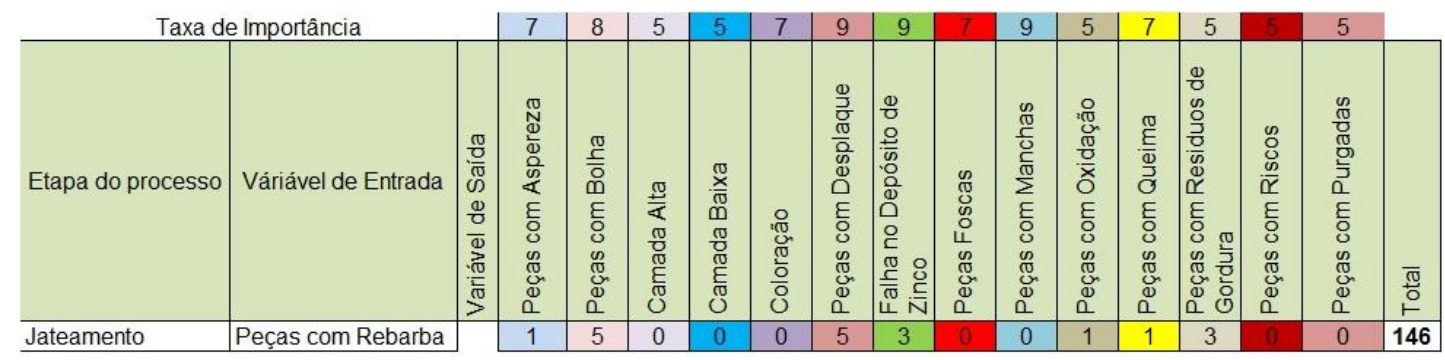

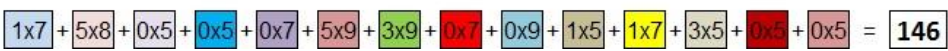

Figura 5 - Exemplo do cálculo do Valor Total da Matriz de Priorização

Além de identificar as variáveis de entrada que apresentam grande influência nas variáveis de saída e que, portanto, devem ser priorizadas no trabalho de melhoria, deve-se estabelecer um sistema de medição adequado, visto que ele servirá para monitorar os efeitos da melhoria durante e após a implantação das soluções. Para isso, Pande et al. (2001) sugerem que sejam identificados os indicadores mais representativos, além de ser verificada a confiabilidade do sistema de medição, a qual envolve equipamentos como paquímetros, balanças, termômetros e outros. Para medições por atributo, onde o produto é analisado como "aprovado" ou "reprovado", sem apresentar valores numéricos, os operadores que avaliam o produto compõem o sistema de medição. Nesse caso, a forma de avaliar o sistema de medição é através do cálculo do índice de coincidência "Kappa". Esse índice mostra a coerência dos resultados obtidos entre os diferentes operadores e os fornecidos por eles mesmos em verificações repetidas, considerando um conjunto de peças previamente selecionadas e classificadas como boas e ruins.

Para calcular o índice Kappa entre dois operadores denominados por A e B, inicialmente devese determinar, dentre as amostras avaliadas, quantas foram consideradas aprovadas por ambos os operadores $\left(\mathrm{X}_{11}\right)$ e quantas foram reprovadas por eles $\left(\mathrm{X}_{22}\right)$. Além disso, é necessário avaliar quantas amostras foram consideradas aprovadas pelo operador $A\left(Y_{a}\right)$ e quantas foram reprovadas $\left(\mathrm{Z}_{\mathrm{a}}\right)$. $\mathrm{O}$ mesmo cálculo deve ser feito para o operador $\mathrm{B}$, obtendo, respectivamente, o $\mathrm{Y}_{\mathrm{b}}$ e o $\mathrm{Z}_{\mathrm{b}}$. $\mathrm{O}$ próximo passo consiste em calcular as proporções observadas, que consiste em dividir cada variável $X_{11}, X_{22}$, $\mathrm{Y}_{\mathrm{a}}, \mathrm{Z}_{\mathrm{a}}, \mathrm{Y}_{\mathrm{b}}$ e $\mathrm{Z}_{\mathrm{b}}$ pelo numero total de amostras avaliadas, gerando respectivamente as variáveis $\mathrm{O}_{11}, \mathrm{O}_{22}$, $\mathrm{OA}_{1}, \mathrm{OA}_{2}, \mathrm{OB}_{1}$ e $\mathrm{OB}_{2}$. Ou seja, os valores $\mathrm{OB}_{1}$ e $\mathrm{OB}_{2}$, por exemplo, são resultantes da divisão $\mathrm{Y}_{\mathrm{b}}$ pelo total da amostra. Visando considerar as peças aprovadas e reprovadas pelos operadores, em seguida são calculadas as proporções esperadas, denominadas $E_{\mathrm{ii}}$, onde $\mathrm{i}$ varia de 1 a 2 , calculadas segundo a Equação 2:

$$
E_{i i}=O A_{i} \times O B_{i}
$$

Equação 2

Por fim, o índice Kappa é calculado seguindo a Equação 3:

$$
\text { Kарpa }=\frac{\left(O_{11}+O_{22}\right)-\left(E_{11}+E_{22}\right)}{1-\left(E_{11}+E_{22}\right)}
$$

De acordo com a o MSA $4^{\text {a }}$ Edição (2010), são aceitáveis valores de índice kappa superiores a 0,75. Para resultados inferiores a esse valor, recomenda-se treinamento dos operadores e reavaliação dos critérios de reprovação das peças.

Ao final dessa fase, determina-se a capacidade inicial do processo e o nível Sigma em que ele se encontra. Para se determinar o índice Sigma, recomenda-se analisar uma amostra de peças com quantidade suficiente para explicitar as alterações do processo em questão. As medições, se por atributo, devem ser classificadas como aprovadas ou reprovadas e, em seguida, deve-se calcular o valor DPMO, conforme mostrado anteriormente. Em seguida, esse valor deve ser localizado na Tabela 1, visando determinar o nível Sigma atual do processo. 


\subsubsection{Fase analisar}

Nessa fase, o objetivo é identificar os problemas decorrentes da fabricação de determinado produto e as suas respectivas causas, baseando-se nos dados coletados na fase anterior. Para auxiliar nesse procedimento, existem vários métodos auxiliares, porém, esse trabalho adotou o FMEA de processo (Failure Mode and Effect Analysis - Analise de Modo e Efeitos de Falha), o qual auxilia a identificar os possíveis modos de falha do processo de fabricação e suas causas, explicitando as falhas críticas que demandarão ações corretivas e preventivas (BRAZ, 2002).

O manual complementar do FMEA da QS 9000 define essa técnica como um grupo de atividades sistêmicas, com o objetivo de reconhecer e avaliar a falha potencial de um processo e seus efeitos, identificar ações que possam eliminar ou reduzir a probabilidade do modo de falha potencial vir a ocorrer e documentar o processo de análise.

Para realizar essa análise, o FMEA de processo utiliza a planilha mostrada na Figura 6, a qual é preenchida, primeiramente, com as etapas do processo a ser analisado, ressaltando as entradas mais críticas, identificadas anteriormente. Em seguida, iniciam-se as análises, identificando as falhas potenciais desse processo, detalhando como poderia ocorrer essa falha e quais efeitos surtiriam com a sua ocorrência. Em função dos seus efeitos, pontua-se a Severidade da falha. Em seguida devem ser identificadas todas as possíveis causas da falha em questão, associando o nível de Ocorrência dessas causas. Em seguida são considerados dois itens importantes para controlar essas causas: se existe algum tipo de controle que possa atuar na causa da falha e se ela poderia ser Detectada na linha antes de ocorrer. Após a definição dos três índices relacionados à Severidade, Ocorrência e Detecção, utilizando uma escala adequada, os mesmos são multiplicados, determinando-se o Número de Prioridade de Risco, denominado RPN (Risk Priority Number). As causas associadas aos RPNs altos devem ser priorizadas para as tomadas de ações corretivas ou preventivas (ESTORILIO; POSSO, 2010). Um exemplo de tabela utilizada para o FMEA é apresentada na Figura 6.

\begin{tabular}{|c|c|c|c|c|c|c|c|c|c|c|c|c|c|}
\hline & & & & & Failure $\mathrm{M}$ & ode & and Effects & Analysis & & & & $\begin{array}{l}\text { FMEA Número: } \\
\text { Data do FMEA: }\end{array}$ & \\
\hline & & Produto : & & & Nível de Revis & & & & & & & Piloto: & \\
\hline Definição & Entrada do & Falha $\mathrm{P}$ & otencial & $\frac{0}{0}$ & Causa & $\frac{\pi}{0}$ & Controle & es Atuais & జూ & & $\begin{array}{c}\text { Ações } \\
\text { Recomendada }\end{array}$ & & \\
\hline Processo & (X's) & MODO & EFEITO & ळे & $\begin{array}{c}\text { Falha } \\
\text { F }\end{array}$ & : & $\begin{array}{c}\text { PREVENÇÃ } \\
\text { O }\end{array}$ & DETECÇÃO & ڤัँ & & & Responstavel & execução \\
\hline $\begin{array}{c}\text { Em qual Etapa } \\
\text { do Processo o X } \\
\text { aparece }\end{array}$ & $\begin{array}{l}\text { X's Priorizados } \\
\text { anteriormente }\end{array}$ & $\begin{array}{l}\text { Como esse } \\
\text { X pode } \\
\text { falhar? }\end{array}$ & $\begin{array}{c}\text { Qual o } \\
\text { efeito dessa } \\
\text { falha? }\end{array}$ & & $\begin{array}{l}\text { O que pode ter } \\
\text { causado essa } \\
\text { falha? }\end{array}$ & & $\begin{array}{c}\text { Quais os modos } \\
\text { de controle } \\
\text { para prevenção } \\
\text { da falha? }\end{array}$ & $\begin{array}{c}\text { Quais os modos } \\
\text { de controle } \\
\text { para detecção } \\
\text { da falha? }\end{array}$ & & & $\begin{array}{c}\text { Qual a ação } \\
\text { Recomendada? }\end{array}$ & $\begin{array}{l}\text { Quem será o } \\
\text { responsável? }\end{array}$ & $\begin{array}{c}\text { Qual o prazo } \\
\text { para execução? }\end{array}$ \\
\hline & & & & & & & & & & & & & \\
\hline & & & & & & & & & & & & & \\
\hline & & & & & & & & & & & & & \\
\hline & & & & & & & & & & & & & \\
\hline & & & & & & & & & & & & & \\
\hline & & & & & & & & & & & & & \\
\hline & & & & & & & & & & & & & \\
\hline & & & & & & & & & & & & & \\
\hline
\end{tabular}

Figura 6 - Planilha para preenchimento do FMEA

Essa fase resulta na definição de problemas críticos, associados às causas que deverão ser priorizadas no trabalho de melhoria que se segue, em função de elas representarem alto risco para o processo e, consequentemente, para o produto resultante.

\subsubsection{Fase implantar melhorias}

Nessa fase, a equipe deve fazer as melhorias no processo existente, traduzindo os dados estatísticos em dados de processo, atuando sobre as causas raízes (ROTONDARO, 2002). De acordo com Henderson e Evans (2000), o objetivo dessa fase é a remoção das causas dos erros, buscando apresentar um desempenho dentro dos limites aceitáveis.

Segundo Pande et al. (2001), é nessa fase que o trabalho de definição, medição e análise apresentam seus resultados. Os autores listam alguns fatores que podem ocultar os benefícios do projeto 
Seis Sigma, como por exemplo, a falta de criatividade, a falha em examinar soluções do início ao fim, a implantação superficial e aleatória e a resistência organizacional. Fioravanti (2005) também ressalta que é importante maximizar os benefícios, aproveitando-se, por exemplo, de soluções que possam atender ou melhorar outras questões.

A principal técnica utilizada nessa fase é o DOE (ANDRIETTA et al., 2005). Essa técnica tem por objetivo detalhar e planejar a quantidade de experimentos a serem realizados, de tal forma que as variáveis de entradas sejam alteradas e seus impactos sobre uma resposta sejam avaliados, possibilitando a identificação da melhor combinação de variáveis (ROTONDARO, 2002). Um exemplo prático da aplicabilidade desse método pode ser visto em (CUNICO et al., 2008). Com base nos resultados obtidos com o auxílio do DOE ou outro método que auxilie na identificação da melhor combinação de variáveis de um processo, visando atingir o melhor resultado possível, realiza-se um teste piloto em pequena escala para identificar as dificuldades e a viabilidade da solução escolhida.

Durante a implantação das melhorias, novas medições devem ser feitas, utilizando os indicadores de desempenho escolhidos inicialmente, visando comprovar a redução ou eliminação do problema. Caso essas medições comprovem os resultados esperados, as melhorias devem ser implantadas em grande escala, visando se aproximar do nível de qualidade 6 Sigma.

\subsubsection{Fase controlar}

A fase de fechamento do DMAIC consiste em identificar meios para manter as melhorias (HENDERSON; EVANS, 2000). Dentre os recursos adotados nessa fase, destacam-se: planos de controle, cartas de controle e processos a prova de erros (YOUNG, 2001).

O "plano de controle" é um documento formal, representado por uma planilha que busca garantir que o processo irá operar dentro dos limites da especificação, minimizando a necessidade de novos ajustes no processo (SCATOLIN, 2005). O documento deve apresentar todas as características do processo, com as dimensões e tolerâncias, além de informar se os dados se referem a uma característica crítica, qual a forma e frequência de medição da característica e qual é o plano de ação ou contenção, caso a característica esteja fora da especificação, incluindo o responsável por essa ação.

A "carta de controle", também chamada de "gráfico de controle", é um registro gráfico dos dados de um evento ao longo do tempo, diante dos limites de controle (RODRIGUES, 2006). Em geral, um gráfico de controle é composto por três linhas paralelas, onde a linha central representa o valor médio característico, a superior representa o limite superior de controle (LSC) e a linha inferior representa o limite inferior de controle (LIC) (VIEIRA, 1999). Caso um ou mais pontos se encontrem fora dos limites da especificação, entende-se que o processo está "fora de controle". A Figura 7 mostra um exemplo de "carta de controle", cujo processo está controlado em função dos valores estarem dentro dos limites pré-estabelecidos.

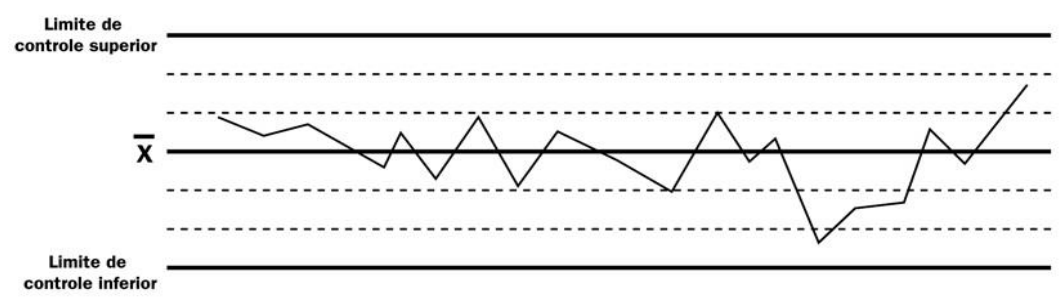

Figura 7 - Exemplo de carta de controle (Elaborada pelas Autoras).

Nessa fase espera-se a "Aprovação do Proprietário do Processo". O líder do projeto Seis Sigma faz uma apresentação dos resultados obtidos e transfere a responsabilidade do plano de controle ao proprietário do processo fabril (SCATOLIN, 2005). Enfim, essa é a última fase do método DMAIC. Considerando que esse trabalho visa mostrar a aplicação do Seis Sigma em uma empresa de pequeno porte, sem o auxílio de consultores especializados, o próximo item apresenta algumas considerações sobre esse perfil de empresa, as quais poderiam impactar em demanda de pequenas modificações na estratégia de aplicação do Seis Sigma, previamente apresentada. 


\subsection{Empresas de pequeno porte}

O critério para se definir o porte da empresa segue as características do país em que ela se localiza e o objetivo da referida classificação (GASPERINI, 2000). Dentre as formas de classificação, pode-se citar o número de empregados, patrimônio líquido, faturamento e outros (OLIVEIRA, 2006).

De acordo com o SEBRAE (Serviço Brasileiro de Apoio à Micro e Pequena Empresa), as pequenas empresas do ramo industrial são classificadas de acordo com o número de empregados, o qual varia de 20 e 99.

Uma revisão feita por Duarte e Ramos (2006) mostra que as MPMEs brasileiras têm as seguintes características:

- Concentração da tomada de decisão nas mãos da Direção (ou empresário) e administração do tipo familiar, o que faz com que a qualidade das decisões possa ser comprometida, mas permite ao processo decisório uma grande agilidade;

- Tomada de decisões com ênfase no curto prazo, o que dificulta o investimento e a manutenção de programas com retornos a médio e longo prazos;

- Empregados com pouca perspectiva de carreira, baixa qualificação e pouco treinamento formal, mas em contrapartida, com boa visão dos processos, produtos e clientes, devido à própria dimensão da empresa;

- Pequeno investimento em tecnologia e inovação;

- Restrição à nichos de mercado ou subordinadas à grandes clientes quando organizadas em rede.

Conforme citado em Moreira e Souza (2004), as MPMEs possuem, frequentemente, um único proprietário ou é propriedade de um pequeno grupo de pessoas. Normalmente, elas são administradas pelo proprietário, o qual se torna o centro das decisões, além de ter o capital financiado basicamente por ele. Analisando essas características, pode-se dizer que os itens críticos para a implantação do Seis Sigma são os empregados com baixa qualificação e pouco treinamento formal, além do baixo potencial para investimentos. Por outro lado, a concentração de poder para tomada de decisões poderia facilitar, considerando o apoio do proprietário da empresa e a agilidade no processo decisório.

Em função das restrições financeiras, quando uma pequena empresa opera com altos índices de retrabalhos, ela poderia chegar ao seu limite e precisar encerrar os seus negócios. Se essa pequena empresa quiser melhorar o seu negócio, utilizando uma estratégia do tipo "Seis Sigma", segundo Brue (2006), antes é necessário alterar alguns de seus paradigmas. Por exemplo; trocar a visão de curto prazo para a de longo prazo, focar no processo e não apenas no produto, compreender que treinamentos são investimentos e não gastos, trocar o comportamento reativo pelo proativo, entre outros.

O Quadro 2 apresenta algumas recomendações sugeridas pelos autores Harry (2003), Antony et al. (2008), Antony et al. (2005) e Harry e Crawford (2004), considerando as dificuldades da pequena empresa e sugestões para a implantação do Seis Sigma. É importante ressaltar a importância do Seis Sigma para a pequena empresa, considerando que ela contribui para eliminar defeitos e retrabalhos na produção, impactando em reduções significativas de custos, o que melhora o desempenho do processo e a qualidade dos produtos resultantes deste.

Quadro 2 - Recomendações para aplicação do Seis Sigma na pequena empresa

\begin{tabular}{|l|l|}
\hline \multicolumn{1}{|c|}{ Principais Dificuldades } & \multicolumn{1}{|c|}{ Recomendações } \\
\hline Criar a Cultura Apropriada & $\begin{array}{l}\text { - Treinamento sobre qualidade } \\
\text { - Envolvimento do proprietário e utilização de sua influência dentro do grupo }\end{array}$ \\
\hline Investimentos Financeiros & - Aguardar o resultado da aplicação em um projeto, para reaplicá-la em outro \\
\hline $\begin{array}{l}\text { Treinamento dos trabalhado- } \\
\text { res envolvidos no projeto de } \\
\text { melhoria }\end{array}$ & $\begin{array}{l}\text { - Contratação de agentes externos para coordenar a implantação do 6 Sigma } \\
\text { - Investir em treinamento de White Belts (40hs) } \\
\text { - Utilizar o conhecimento acadêmico / parceria com universidades. }\end{array}$ \\
\hline
\end{tabular}

Considerando os conceitos e revisões apresentados, o próximo item detalha a estratégia de aplicação do Seis Sigma em uma empresa de pequeno porte, mostrando resultados práticos obtidos em ambiente industrial. 


\section{Aplicação do Seis Sigma em uma empresa de pequeno porte}

O caso escolhido para a aplicação do Seis Sigma, utilizando o método DMAIC, é uma pequena empresa com 60 funcionários, localizada em Curitiba, especializada no tratamento de superfícies de peças seriadas para as indústrias automotivas. Entre os tratamentos executados nessa empresa, destacase o "processo de zincagem", cujo objetivo é o de proteger a superfície das peças contra a corrosão. Esse processo consiste em uma limpeza inicial das peças, com posterior imersão em um tanque com zinco, onde íons de zinco são transferidos para a peça por eletrólise. As etapas envolvidas no processo de zincagem podem ser vistas no fluxograma mostrado na Figura 8.

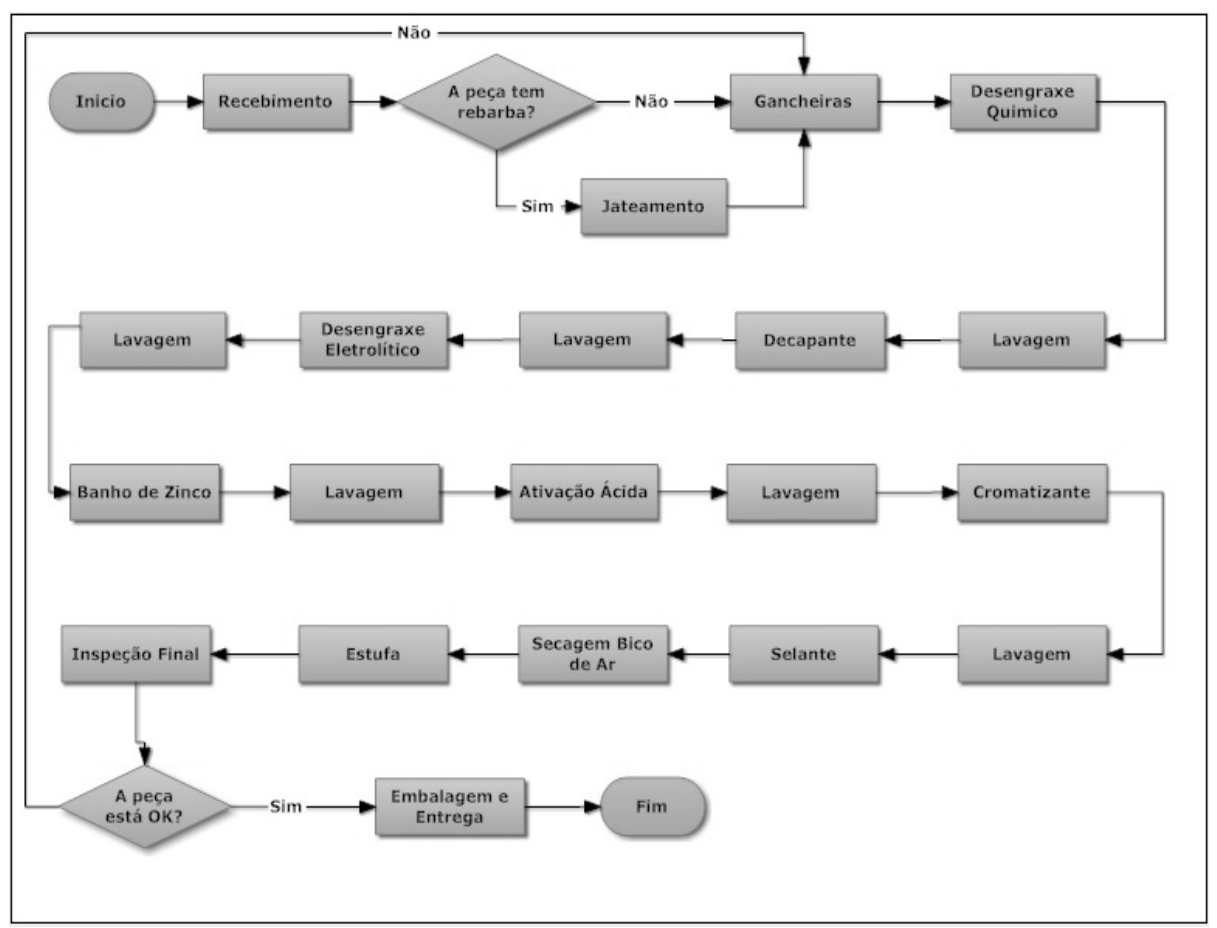

Figura 8 - Fluxograma do Processo de Zincagem (Elaborada pelas autoras)

Os próximos itens apresentam como o DMAIC foi aplicado nesse processo.

\subsection{Fase definir}

A primeira fase do projeto teve início pela definição da equipe. Esta foi composta por dez pessoas, incluindo o proprietário da empresa, o gerente da qualidade, a supervisora da produção, dois analistas da qualidade, três operadores da linha de produção e uma das autoras desse trabalho, a qual se colocou como coach (treinadora) do projeto. A segunda autora atuou na orientação da aplicação do Seis Sigma em campo e na verificação dos relatórios parciais e final. Em função da atuação dentro da empresa, os membros da equipe se colocaram em papéis compatíveis aos apresentados no Quadro 1. Em seguida, foi definido o cronograma de aplicação e outros detalhes que comporiam a Carta de Projeto.

Considerando a experiência dos colaboradores e da alta gerência, ficou claro que o principal problema da empresa era o atraso nas entregas dos produtos para o cliente final. Em uma rápida análise, a equipe concluiu que os atrasos nas entregas tinham como principal motivo a alta taxa de retrabalho, o que impactava em refazer o processo de tratamento superficial, passando por todas as etapas apresentadas no fluxograma da Figura 8. Baseando-se nos dados de meses anteriores, pôde-se verificar que as taxas de retrabalho chegavam a $36 \%$ das peças produzidas, explicitando o problema que esse índice representava para a empresa e para o consumidor. Como meta inicial do projeto, a equipe sugeriu que a taxa de retrabalho fosse reduzida para $10 \%$ das peças produzidas, considerando que esse perfil de processo possui perdas naturais devido ao grande número de variáveis não controladas. 
Sendo assim, definiu-se a Missão do Projeto (Declaração da Meta) através da técnica 5W1H, ou seja, definiu-se que "os retrabalhos seriam reduzidos a um mínimo de $10 \%$ das peças produzidas, com o objetivo de reduzir os atrasos nas entregas, utilizando a abordagem DMAIC entre Setembro e Dezembro de 2010". Após essas definições, detalhou-se a Carta de Projeto, apresentada no Quadro 3.

Quadro 3 - Carta de projeto (Elaborada pelas autoras)

\section{CARTA DE PROJETO}

Declaração do Problema: Os clientes se sentem prejudicados pelos atrasos nas entregas dos produtos devido às altas taxas de retrabalho que chegam a atingir mais de $30 \%$ dos produtos produzidos.

Declaração de Meta: Reduzir os atrasos nas entregas através da redução de retrabalhos para menos de $10 \%$ das peças produzidas.

Diretrizes da Equipe: A equipe se reunirá uma vez por semana em data a ser definida nas reuniões para discutir os resultados e as novas decisões.

Membros da Equipe: Proprietário da empresa, gerente de qualidade, analista de qualidade1, analista de qualidade 2, operador de laboratório, líder de produção, operador da inspeção final, supervisora de produção e consultores externos (autoras desse trabalho).

Plano Preliminar de Projeto: Datas previstas para a conclusão de cada etapa do DMAIC: Definir (15/Set/2010), Medir (15/Out/2010), Analisar (15/Nov/2010), Implantar (15/Dez/2010), Controlar (30/Dez/2010).

\subsection{Fase medir}

Com o objetivo de entender melhor o processo de zincagem e identificar os procedimentos mais críticos, a equipe Seis Sigma elaborou um Mapa do Processo, conforme mostrado na Figura 3. A técnica consiste em detalhar como as peças chegam a cada etapa e quais são as variáveis envolvidas como, por exemplo, temperatura, tempo, amperagem e outros. Essas informações são chamadas de "variáveis de entrada" e são descritas do lado esquerdo de cada etapa do processo. Em seguida, detalha-se o estado esperado das peças ao final de cada etapa do processo e se há alguma inspeção nesta etapa. Essas informações são denominadas variáveis de saída e são descritas do lado direito. Durante o mapeamento do processo de zincagem foram identificadas 18 etapas, as quais somam um total de 48 entradas e 39 saídas, conforme mostrado parcialmente no Quadro 4.

A partir da análise do Mapa do Processo, a equipe definiu que as principais variáveis de saída a serem consideradas na Matriz de Priorização se referiam às saídas da etapa de inspeção final, ou seja, os possíveis defeitos que poderiam ser encontrados nas peças após passarem por todas as etapas do processo de zincagem. 
Quadro 4 - Mapa do processo (Elaborado pelas autoras)

\begin{tabular}{|c|c|c|}
\hline Variável de Entrada & $\begin{array}{l}\text { Etapas do Processo } \\
\text { de Zincagem }\end{array}$ & $\begin{array}{c}\text { Variável de Saída } \\
\text { (Métodos de Avaliação) }\end{array}$ \\
\hline $\begin{array}{l}\text { Peças com rebarba } \\
\text { Pressão de jateamento } \\
\text { Tempo de jateamento }\end{array}$ & \multirow[t]{2}{*}{ Jateamento } & \multirow[t]{2}{*}{ Peças Livres Rebarba } \\
\hline Qtde de peças no jateamento & & \\
\hline $\begin{array}{l}\text { Gancheira correta para a peça } \\
\text { Estado da Gancheira }\end{array}$ & Engancheiramento & $\begin{array}{l}\text { Peças Presas às Gancheiras } \\
\text { Análise Visual } \\
\end{array}$ \\
\hline $\begin{array}{l}\text { Peças com óleo e graxa } \\
\text { Concentração e Tempo da solução alcalina }\end{array}$ & Desengraxe Químico & Peças sem Óleos e Graxas \\
\hline $\begin{array}{l}\text { Tempo de troca do desengraxante } \\
\text { Peças com impurezas na região da solda } \\
\text { Tempo de permanência da peça }\end{array}$ & & Análise Visual \\
\hline Peças com excesso da solução de desengraxe & Lavagem & Peças sem Excesso da Solução \\
\hline $\begin{array}{l}\text { Peças com carepa } \\
\text { Concentração de ácidos } \\
\text { Tempo de troca do decapante } \\
\text { Tempo de permanência da peça } \\
\end{array}$ & Decapagem Ácida & Peça sem Carepa \\
\hline Peças: excesso da solução de decapagem & Lavagem & Peças sem Excesso da Solução \\
\hline $\begin{array}{l}\text { Peças com micro carepas } \\
\text { Concentração do desengraxante } \\
\text { Tempo de troca do desengraxante } \\
\text { Tempo de permanência da peça } \\
\text { Amperagem do desengraxe eletrolítico }\end{array}$ & Desengraxe Eletrolítico & Peças com Limpeza Profunda \\
\hline Peças com excesso da solução de desengraxe & Lavagem & Peças sem Excesso da Solução \\
\hline $\begin{array}{l}\text { Peças limpas } \\
\text { Concentração de zinco } \\
\text { Concentração de soda } \\
\text { Adição de aditivos } \\
\text { Amperagem do banho de zinco } \\
\text { Tempo de permanência da peça } \\
\end{array}$ & Banho de Zinco & Análise de Camada intra-processo \\
\hline Peças com excesso de banho de zinco & Lavagem & Peças sem Excesso da Solução \\
\hline $\begin{array}{l}\text { Peças zincadas } \\
\text { Ph da solução de ativação ácida } \\
\text { Tempo de troca da solução de ativação ácida }\end{array}$ & Ativação Ácida & Peças Ativadas \\
\hline Peças - excesso de ativação Ácida & Lavagem & Peças sem Excesso da Solução \\
\hline $\begin{array}{l}\text { Peça ativada } \\
\text { Concentração do cromato } \\
\text { PH da solução cromatizante } \\
\text { Tempo de troca da solução cromatizante } \\
\text { Concentração de Ferro } \\
\text { Tempo de permanência da peça }\end{array}$ & Cromatizante & Peças Cromatizadas \\
\hline Peças - excesso de cromatizante & Lavagem & Peças sem Excesso da Solução \\
\hline $\begin{array}{l}\text { Peças cromatizadas } \\
\text { Concentração de selante } \\
\text { Ph da solução de selante }\end{array}$ & Selante & Peças Seladas \\
\hline Peças molhadas & Secagem Bico de Ar & Peças Úmidas \\
\hline Temperatura da estufa & Estufa & Peças Secas \\
\hline Peças Finalizadas & Inspeção Final & $\begin{array}{l}\text { Peças conforme especificações e } \\
\text { outras avaliações }\end{array}$ \\
\hline
\end{tabular}


Com o objetivo de priorizar os critérios de reprovação, a equipe atribuiu uma Taxa de Importância (TI) variável de 5 a 9 para cada um dos 14 defeitos identificados na inspeção final, conforme mostrado na Tabela 2 e na Figura 9. Para determinar a TI, utilizou-se um Gráfico de Pareto, preenchido a partir do número de ocorrências de cada problema, constatado entre março/2010 e agosto/2010 (Ver Figura 9). A partir do gráfico gerado, a equipe definiu que as seguintes ocorrências gerariam as seguintes TIs: acima de $10 \%$ (TI 9); entre $5 \%$ e $10 \%$ (TI 8); entre $1 \%$ e 5\% (TI 7); abaixo de $1 \%$ (TI 5). Os dados utilizados na construção do gráfico são apresentados na Tabela 2 e o Gráfico de Pareto é mostrado na Figura 9.

Tabela 2 - Dados para construção do Gráfico de Pareto

\begin{tabular}{|l|c|c|c|}
\hline \multicolumn{1}{|c|}{ Problemas } & $\begin{array}{c}\text { Número de } \\
\text { Ocorrências }\end{array}$ & Percentagem & $\begin{array}{c}\text { Percentagem } \\
\text { Acumulada }\end{array}$ \\
\hline Manchas & $\mathbf{4 2 0 6}$ & 36,32 & 36,32 \\
\hline Falha no depósito & $\mathbf{2 9 6 0}$ & 25,56 & 61,88 \\
\hline Desplaque & $\mathbf{1 6 6 5}$ & 14,38 & 76,25 \\
\hline Bolhas & $\mathbf{9 8 0}$ & 8,46 & 84,72 \\
\hline Aspereza & $\mathbf{4 3 2}$ & 3,73 & 88,45 \\
\hline Coloração & $\mathbf{4 2 8}$ & 3,70 & 92,14 \\
\hline Queima & $\mathbf{3 3 8}$ & 2,92 & 95,06 \\
\hline Fosca & $\mathbf{2 9 0}$ & 2,50 & 97,56 \\
\hline Oxidação & $\mathbf{9 8}$ & 0,85 & 98,41 \\
\hline Camada Baixa & $\mathbf{9 6}$ & 0,83 & 99,24 \\
\hline Riscos & $\mathbf{5 7}$ & 0,49 & 99,73 \\
\hline Camada Alta & $\mathbf{1 9}$ & 0,16 & 99,90 \\
\hline Gordura & $\mathbf{8}$ & 0,07 & 99,97 \\
\hline Purgadas & $\mathbf{4}$ & 0,03 & 100,00 \\
\hline Total & $\mathbf{1 1 5 8 1}$ & 100,0 & \\
\hline
\end{tabular}

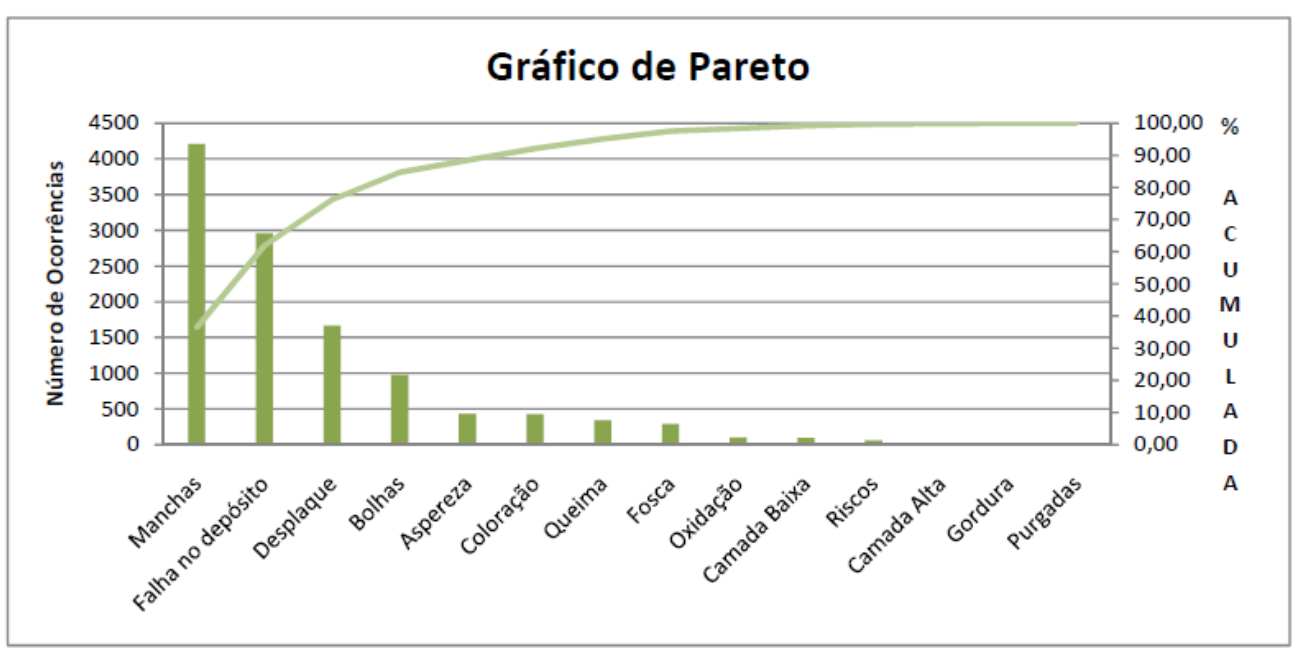

Figura 9 - Gráfico de Pareto

A partir do gráfico de Pareto, concluiu-se que o problema mais frequente é o aparecimento de manchas nas peças após o banho de Zinco, seguido pela falha no depósito de Zinco e desplaque da camada, os quais receberam taxa de importância 9 (TI 9). A ocorrência de bolhas foi o próximo item e recebeu TI 8. Em seguida, apresentaram-se aspereza, coloração, ocorrência de queima e peças foscas com TI 7. Entre as menores ocorrências, tem-se a oxidação das peças, riscos, peças com gordura, purgadas e problemas de camada de Zinco em excesso ou em falta, que receberam TI 5 (Ver Tabela 2) .

Depois de priorizar os defeitos, fez-se necessário entender quais etapas do Processo de Zincagem apresentavam maior influência na ocorrência dessas não conformidades. Para isso, iniciou-se o preenchimento da "Matriz de Priorização", onde a primeira coluna apresenta todas as variáveis de entrada descritas no Mapa do Processo e a segunda linha apresenta todos os defeitos com suas respectivas taxas de importância. Para relacionar as variáveis de entrada com cada defeito, a equipe estipulou valores de correlação de acordo com os seguintes critérios: (0) Nenhuma Correlação; (1) Baixa Correlação; (3) Média Correlação e (5) Alta Correlação (Ver Tabela 3). O total resultante na última coluna de cada linha se refere à somatória da multiplicação do (nível de correlação da entrada com a saída) com (a taxa de importância). Ou seja, para a primeira linha, a seguinte conta foi realizada: Somatória 
$\left(\sum\right)=(1 * 7)+(5 * 8)+(0 * 5)+(0 * 5)+(0 * 7)+(5 * 9)+(3 * 9)+(0 * 7)+(0 * 9)+(1 * 5)+(1 * 7)+(3 * 5)+$ $(0 * 5)+(0 * 5)=146$.

Tabela 3 - Matriz de priorização

\begin{tabular}{|c|c|c|c|c|c|c|c|c|c|c|c|c|c|c|c|c|}
\hline Taxa de Importância & & 7 & 8 & 5 & 5 & 7 & 9 & 9 & 7 & 9 & 5 & 7 & 5 & & 5 & \\
\hline Variável de Entrada & 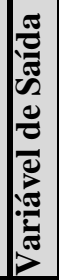 & 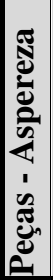 & 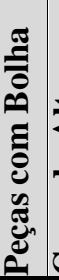 & 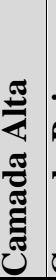 & 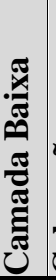 & 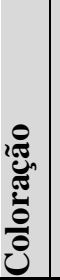 & & 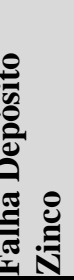 & 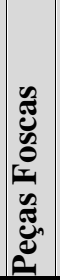 & 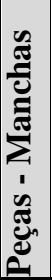 & 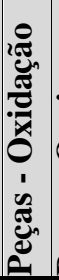 & 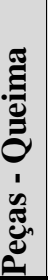 & 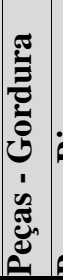 & & & $\stackrel{\bar{\pi}}{0}$ \\
\hline Peças com Rebarba & & 1 & 5 & $\mathbf{0}$ & $\mathbf{0}$ & $\mathbf{0}$ & 5 & $\mathbf{3}$ & $\mathbf{0}$ & $\mathbf{0}$ & $\mathbf{1}$ & 1 & 3 & $\mathbf{0}$ & $\mathbf{0}$ & 146 \\
\hline Pressão de Jateamento & & 3 & 3 & 0 & 0 & 0 & 3 & 3 & 3 & 1 & 0 & 0 & 0 & 0 & 0 & 129 \\
\hline Tempo de Jateamento & & 0 & 3 & 0 & 0 & 0 & 1 & 1 & 0 & 0 & 0 & 0 & 0 & 0 & 0 & 42 \\
\hline Quantidade de Peças no Jateamento & & 0 & 3 & 0 & 0 & 0 & 3 & 1 & 0 & 0 & 0 & 0 & 0 & 0 & 0 & 60 \\
\hline Gancheira Correta para a Peça & & 0 & 3 & 0 & 0 & 0 & 3 & 3 & 0 & 0 & 0 & 3 & 0 & 3 & 0 & 114 \\
\hline Estado da Gancheira & & 0 & 0 & 1 & 1 & 0 & 0 & 5 & 0 & 0 & 0 & 3 & 0 & 0 & & 76 \\
\hline Peças com Óleo e Graxa & & 0 & 5 & 0 & 0 & 1 & 5 & 3 & 3 & 3 & 0 & 0 & 5 & 0 & 0 & 192 \\
\hline Concentração da Solução Alcalina & & 0 & 5 & 0 & 0 & 0 & 3 & 3 & 0 & 0 & 0 & 0 & 5 & 0 & 0 & 119 \\
\hline Temperatura da Solução Alcalina & & 0 & 5 & 0 & 0 & 0 & 3 & 3 & 0 & 0 & 0 & 0 & 5 & 0 & 0 & 119 \\
\hline Tempo de Troca do Desengraxante & & 0 & 3 & 0 & 0 & 0 & 3 & 3 & 0 & 0 & 0 & 0 & 3 & 0 & 0 & 93 \\
\hline Peças com Impurezas & & 1 & 5 & 1 & 5 & 3 & 5 & 5 & 3 & 1 & 1 & 5 & 5 & 5 & & 333 \\
\hline Tempo de Permanência da Peça & & 0 & 5 & 0 & 0 & 0 & 5 & 3 & 0 & 0 & 0 & 0 & 5 & 0 & $\overline{0}$ & 137 \\
\hline Peças com Excesso do Desengraxe Quí & & 0 & 5 & 0 & 0 & 0 & 5 & 3 & 0 & 0 & 0 & 0 & 5 & 0 & & 137 \\
\hline Peças com Carepa & & 5 & 3 & 0 & 0 & 0 & 5 & 1 & 0 & 0 & 0 & 0 & 0 & 0 & 0 & 113 \\
\hline Concentração de Ácidos & & 0 & 3 & 0 & 0 & 0 & 3 & 1 & 0 & 0 & 0 & 0 & 0 & 0 & 0 & 60 \\
\hline Tempo de Troca do Decapante & & 3 & 5 & 0 & 0 & 0 & 3 & 0 & 0 & 0 & 0 & 0 & 0 & 0 & 0 & 88 \\
\hline Tempo de Permanênci & & 0 & 5 & 0 & 0 & 0 & 5 & 1 & 0 & 0 & 0 & 0 & 0 & 0 & & 94 \\
\hline Peças com Excesso da Decapagem Ácida & & 1 & 5 & 0 & 0 & \begin{tabular}{|l|l|l|l}
0 & \\
\end{tabular} & 3 & 1 & 0 & 0 & 3 & 0 & 0 & 0 & 0 & 98 \\
\hline Peças com micro carepas & & 0 & 3 & 0 & 0 & 0 & 3 & 1 & 0 & 0 & 0 & 0 & 0 & 0 & & 60 \\
\hline Tempo de Troca do Desen & & 0 & 3 & 0 & 0 & 0 & 1 & 0 & 0 & 0 & 1 & 1 & 0 & 0 & & 45 \\
\hline Tempo de Permanência da Peça & & 1 & 3 & 0 & 0 & 0 & 3 & 0 & 1 & 1 & 0 & 3 & 0 & 0 & 0 & 95 \\
\hline Amperagem do Desengraxe Eletrolítico & & 0 & 3 & 0 & 0 & 0 & 3 & 1 & 0 & 0 & 0 & 3 & 0 & 0 & 0 & 81 \\
\hline Peças com Excesso do Desengraxe Eletrolítico & & 1 & 3 & 0 & 0 & 0 & 3 & 0 & 0 & 0 & 0 & 0 & 0 & 0 & 0 & 58 \\
\hline Peças Limpas & & 5 & 5 & 0 & 0 & 3 & 5 & 5 & 3 & 3 & 1 & 3 & 3 & 0 & 3 & 290 \\
\hline Concentração de Zinco & & 0 & 3 & 5 & 5 & 0 & 5 & 5 & 3 & 3 & 0 & 5 & 0 & 0 & 0 & 247 \\
\hline Concentração de Soda & & 1 & 0 & 0 & 0 & 0 & 1 & 3 & 3 & 3 & 0 & 0 & 0 & 0 & & 91 \\
\hline Adição de Aditivos & & 0 & 3 & 5 & 5 & 3 & 5 & 5 & 5 & 5 & 0 & 3 & 0 & 0 & & 291 \\
\hline Amperagem do Banho de Zinco & & 3 & 5 & 5 & 5 & 1 & 5 & 5 & 1 & 0 & 0 & 5 & 0 & 0 & 0 & 250 \\
\hline Tempo de Permanência da Peça & & 0 & 5 & 5 & 5 & 0 & 5 & 5 & 3 & 0 & 0 & 5 & 5 & 5 & 5 & 311 \\
\hline Peças com Excesso do Banho de Zinco & & 1 & 0 & 0 & 0 & 3 & 0 & 0 & 0 & 5 & 1 & 0 & 0 & 0 & 1 & 83 \\
\hline Peças Zincadas & & 0 & 0 & 0 & 0 & 5 & 0 & 0 & 5 & 5 & 3 & 0 & 0 & 0 & 0 & 130 \\
\hline PH uniformizar da Soluc & & 0 & 0 & 0 & 0 & 5 & 0 & 0 & $3 \mid$ & 5 & 0 & 0 & 0 & 0 & & 101 \\
\hline Tempo de Troca da Solução de ativação Ácida & & 0 & 0 & 0 & 0 & 5 & 0 & 0 & 3 & 3 & 0 & 0 & 0 & 0 & 0 & 83 \\
\hline Peças com Excesso da Ativação Ácida & & 0 & 0 & 0 & 0 & 3 & 0 & 0 & 1 & 3 & 1 & 0 & 0 & 0 & 1 & 65 \\
\hline Peça Ativada & & 0 & 0 & 0 & 0 & 5 & 0 & 0 & 0 & 5 & 1 & 0 & 0 & 0 & 0 & 85 \\
\hline Concentração do Cromato & & 0 & 0 & 0 & 0 & 5 & 0 & 0 & 5 & 5 & 3 & 0 & 0 & 0 & 3 & 145 \\
\hline pH da Solução Cromatizante & & 0 & 0 & 0 & 0 & 5 & 0 & 0 & 0 & 5 & 0 & 0 & 0 & 0 & 0 & 80 \\
\hline Tempo de Troca da Solução Crom & & 0 & 0 & 0 & 0 & 3 & 0 & 0 & 0 & 5 & 3 & 0 & 0 & 0 & 3 & 96 \\
\hline Concentração de Ferro & & 0 & 0 & 0 & 0 & 3 & 0 & 0 & 0 & 1 & 5 & 0 & 0 & 0 & 5 & 80 \\
\hline e Permanência da Peça & & 0 & 0 & 0 & 0 & 5 & 0 & 0 & 1 & 5 & 3 & 0 & 0 & 0 & 0 & 102 \\
\hline Peças com Excesso de Cromatizante & & 0 & 0 & 0 & 0 & 3 & 0 & 0 & 0 & 3 & 1 & 0 & 0 & 0 & 3 & 68 \\
\hline Peças Cromatizadas & & 0 & 0 & 0 & 0 & 3 & 0 & 0 & 0 & 5 & 5 & 0 & 0 & 0 & 0 & 91 \\
\hline Concentração de Selante & & 0 & 0 & 0 & 0 & 5 & 0 & 0 & 0 & 3 & \begin{tabular}{|l|}
5 \\
\end{tabular} & 0 & \begin{tabular}{|l|}
0 \\
\end{tabular} & 0 & 5 & 112 \\
\hline PH da Solução de Selante & & 0 & 0 & 0 & 0 & 3 & 0 & 0 & 0 & 3 & 3 & 0 & 0 & 0 & 0 & 63 \\
\hline Fur & & 0 & 0 & 0 & 0 & 3 & 0 & 0 & 0 & 5 & 5 & 0 & 0 & 0 & & 91 \\
\hline Temperatura da Estufa & & 0 & 0 & 0 & 0 & 3 & 3 & 0 & 0 & 5 & 3 & 3 & 0 & 0 & 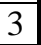 & 144 \\
\hline
\end{tabular}


A interpretação dos resultados obtidos na última coluna, relacionada ao total de cada variável de entrada, significa que os valores maiores devem ser as entradas prioritárias para o estudo, pois possuem forte correlação com alguns defeitos que vem ocorrendo com frequência no processo. Sendo assim, após a elaboração da matriz de priorização e o cálculo do valor total para cada variável de entrada, a matriz foi classificada em ordem decrescente de valor total, determinando as variáveis de entrada e etapas do processo a serem priorizadas.

A equipe definiu que as variáveis de entrada que apresentassem o valor total acima de 145 deveriam ser priorizadas, restringindo as ações de melhoria às oito principais variáveis de entrada, apresentadas na Tabela 4.

Tabela 4 - Principais variáveis de entrada do processo de zincagem

\begin{tabular}{|l|c|}
\hline \multicolumn{1}{|c|}{ Variáveis de Entrada } & Total obtido na Matriz de Priorização \\
\hline 1. Peças com Impurezas na região da Solda & 333 \\
\hline 2. Tempo de Permanência da Peça no banho de Zinco & 311 \\
\hline 3. Adição de Aditivos no banho de Zinco & 291 \\
\hline 4. Peças Limpas (não chegam limpas para o banho Zinco) & 290 \\
\hline 5. Amperagem do Banho de Zinco & 250 \\
\hline 6. Concentração de Zinco & 247 \\
\hline 7. Peças com Óleo e Graxa & 192 \\
\hline 8. Peças com Rebarba & 146 \\
\hline
\end{tabular}

Com o objetivo de garantir medições confiáveis, no início do projeto Seis Sigma os dois operadores responsáveis pela inspeção final dos produtos foram avaliados, considerando as medições por atributo. Para tanto, foram utilizadas 20 peças, previamente analisadas pelo gerente da qualidade, e cada peça foi analisada três vezes por esses inspetores. Os dados obtidos pelos inspetores foram comparados entre si e com o padrão estipulado, gerando três índices Kappa, conforme mostrado nas Figuras 10 e 11. Como os três valores foram superiores a 0,75 , entende-se que o sistema de medição foi aprovado, conforme explicado anteriormente. Detalhes sobre o cálculo desse índice podem ser encontrados em MSA 4 a Edição (2010).

\begin{tabular}{|c|c|c|c|}
\hline \multicolumn{4}{|c|}{ Valores Iniciais } \\
\hline & \multicolumn{3}{|c|}{ Operador 2 } \\
\hline Operador 1 & OK & NOK & Total \\
\hline OK & 42 & 3 & 45 \\
\hline NOK & 2 & 15 & 17 \\
\hline Total & 44 & 18 & 62 \\
\hline \multicolumn{4}{|c|}{ Padrão } \\
\hline \multicolumn{4}{|c|}{} \\
\hline Operador 1 & OK & NOK & Total \\
\hline OK & 42 & 0 & 42 \\
\hline NOK & 3 & 15 & 18 \\
\hline Total & 45 & 15 & 60 \\
\hline \multicolumn{4}{|c|}{ Padrão } \\
\hline \multicolumn{4}{|c|}{} \\
\hline Operador 2 & OK & NOK & Total \\
\hline OK & 42 & 0 & 42 \\
\hline NOK & 4 & 14 & 18 \\
\hline Total & 46 & 14 & 60 \\
\hline
\end{tabular}

\begin{tabular}{|c|c|c|c|}
\hline \multicolumn{4}{|c|}{ Proporções Observadas } \\
\hline & \multicolumn{3}{|c|}{ Operador 2} \\
\hline Operador 1 & OK & NOK & Total \\
\hline OK & 0,67741935 & 0,0483871 & 0,72580645 \\
\hline NOK & 0,03225806 & 0,24193548 & 0,27419355 \\
\hline Total & 0,70967742 & 0,29032258 & 1 \\
\hline & \multicolumn{3}{|c|}{ Padrão } \\
\hline Operador 1 & OK & NOK & Total \\
\hline OK & 0,7 & 0 & 0,7 \\
\hline NOK & 0,05 & 0,25 & 0,3 \\
\hline Total & 0,75 & 0,25 & 1 \\
\hline & \multicolumn{3}{|c|}{ Padrão } \\
\hline Operador 2 & OK & NOK & Total \\
\hline OK & 0,7 & 0 & 0,7 \\
\hline NOK & 0,06666667 & 0,23333333 & 0,3 \\
\hline Total & 0,76666667 & 0,23333333 & 1 \\
\hline
\end{tabular}

\begin{tabular}{|c|c|c|}
\hline \multicolumn{3}{|c|}{ Proporcóes Esperadas } \\
\hline & \multicolumn{2}{|c|}{ Operador 2} \\
\hline Operador 1 & OK & NOK \\
\hline OK & 0,51508845 & 0,210718 \\
\hline NOK & 0,19458897 & 0,07960458 \\
\hline & \multicolumn{2}{|c|}{ Padrão } \\
\hline Operador 1 & OK & NOK \\
\hline OK & 0,525 & 0,175 \\
\hline NOK & 0,225 & 0,075 \\
\hline & \multicolumn{2}{|c|}{ Padrão } \\
\hline Operador 2 & OK & NOK \\
\hline $\mathrm{OK}$ & 0,53666667 & 0,16333333 \\
\hline NOK & 0,23 & 0,07 \\
\hline
\end{tabular}

Figura 10 - Matrizes de Proporções para Cálculo do Índice Kappa

\begin{tabular}{|c|}
\hline Indice Kappa entre Operadores A e B \\
\hline Kappa A-B $=\frac{(0,67742+0,24193)-(0,51509+0,07960)}{1-(0,51509+0,07960)}=0,801$ \\
\hline
\end{tabular}

\begin{tabular}{|lcccc|c|}
\hline \multicolumn{7}{|c|}{ Indice Kappa entre Operador A e Padrão } \\
\hline Kappa $A=(0,7+0,25)$ & $-(0,525+0,075)$ & \multirow{2}{*}{0,875} \\
\hline & 1 & $-0,525+0,075)$ & \\
\hline
\end{tabular}

\begin{tabular}{|l|c|}
\hline \multicolumn{5}{|c|}{ Indice Kappa entre Operadore B e Padrão } \\
\hline Kappa B $=\frac{(0,7+0,233333)-(0,53667+0,07)}{2}=0,83$ \\
\hline $1+0,53667+0,07)$ \\
\hline
\end{tabular}

Figura 11 - Índice Kappa da Inspeção Final 
Com o objetivo de calcular o Nível Sigma inicial do projeto, foram utilizados os valores médios, referentes ao número de peças reprovadas na inspeção final, entre os meses de março/2010 a agosto/2010, considerando os valores DPMO (Defeitos por Milhão de Oportunidades) mostrados na Tabela 1. Na Tabela 5 são apresentados os indicadores DPMO dos meses de março, abril, maio, junho, julho e agosto de 2010, os correspondentes Níveis Sigma e a média Sigma desses meses, considerando o valor inteiro sem casas decimais.

Tabela 5 - Nível Sigma no início do projeto

\begin{tabular}{c|c|c|c|c|c}
\hline \multicolumn{7}{|c}{ Dados da Linha Manual } \\
\hline Mês/2010 & Qtde Produzida & Qtde Reprovada & Percentagem & DPMO & Nível Sigma \\
\hline Março & 5029 & 921 & 18,3 & $\mathbf{1 8 3 . 1 3 8}$ & $\mathbf{3}$ \\
\hline Abril & 9259 & 1360 & 14,7 & $\mathbf{1 4 6 . 8 8 4}$ & $\mathbf{3}$ \\
\hline Maio & 3404 & 1229 & 36,1 & $\mathbf{3 6 1 . 0 4 6}$ & $\mathbf{2}$ \\
\hline Junho & 11966 & 3015 & 25,2 & $\mathbf{2 5 1 . 9 6 4}$ & $\mathbf{2}$ \\
\hline Julho & 8821 & 1757 & 19,9 & $\mathbf{1 9 9 . 1 8 4}$ & $\mathbf{2}$ \\
\hline Agosto & 5123 & 1739 & 33,9 & $\mathbf{3 3 9 . 4 5 0}$ & $\mathbf{2}$ \\
\hline Média & 7267 & 1670,16667 & 22,9828907 & $\mathbf{2 2 9 . 8 2 9}$ & $\mathbf{2}$ \\
\hline
\end{tabular}

Conforme mostrado na Tabela 5, o histórico do processo de zincagem apresentava, no início do mês de setembro, um Nível 2 Sigma como média resultante desse processo. De acordo com a Tabela 1 , o nível 2 Sigma significa comprometer até $25 \%$ das vendas em custos pela não qualidade. No caso do processo em estudo, os custos pela não qualidade eram provenientes dos retrabalhos de peças reprovadas na inspeção final.

Depois de analisar as etapas do processo, as entradas e saídas de cada subprocesso e de priorizar as principais variáveis de entrada, a fase seguinte do DMAIC tem por objetivo analisar o que pode estar acontecendo em cada uma das entradas priorizadas que comprometem o produto final.

\subsection{Fase analisar}

Para analisar as falhas e as causas dessas falhas, identificadas no processo, partiu-se da análise das 8 variáveis de entrada resultantes da Matriz de Priorização, mostradas na Tabela 4. Essas variáveis foram inseridas na planilha do FMEA de processo, visando explorar as possíveis causas dessas ocorrências. Visando apresentar como elas foram analisadas, as duas variáveis que apresentaram o maior índice de risco (NPR) são apresentadas nos Quadros 5, 6 e 7. Em seguida, para cada modo de falha, a equipe descreveu os efeitos causados por essas falhas, caso elas viessem a ocorrer, descrita na coluna "Efeitos da Falha", estipulando valores entre 0 e 10 para a Severidade desses efeitos.

Quadro 5 - FMEA de Processos: falhas potenciais e grau de severidade

\begin{tabular}{|l|l|c|l|l|}
\hline $\begin{array}{l}\text { Definição } \\
\text { Etapa do } \\
\text { Processo }\end{array}$ & $\begin{array}{l}\text { Entrada do } \\
\text { Processo }\end{array}$ & MODOS DE FALHA & \multicolumn{2}{|c|}{ Falha Potencial } \\
\cline { 3 - 6 } $\begin{array}{l}\text { Desengraxe } \\
\text { Químico }\end{array}$ & $\begin{array}{l}\text { Peças com } \\
\text { Impurezas }\end{array}$ & $\begin{array}{c}\text { Peças com } \\
\text { Impurezas na } \\
\text { Região da Solda }\end{array}$ & $\begin{array}{l}\text { Aspereza, Bolha, Coloração, desplaque, falha no } \\
\text { depósito, peças foscas, manchas, oxidação, queima, } \\
\text { gordura, purgadas. }\end{array}$ & 8 \\
\hline $\begin{array}{l}\text { Banho de } \\
\text { Zinco }\end{array}$ & $\begin{array}{l}\text { Peças } \\
\text { Limpas }\end{array}$ & $\begin{array}{c}\text { Peças com óleos e } \\
\text { graxas }\end{array}$ & $\begin{array}{l}\text { Aspereza, Bolha, Coloração, desplaque, falha no } \\
\text { depósito, peças foscas, manchas, oxidação, queima, } \\
\text { gordura, purgadas. }\end{array}$ & 8 \\
\hline
\end{tabular}

Posteriormente, a equipe avaliou as possíveis causas que conduziriam a essas falhas, desencadeando o preenchimento da coluna "Causa Potencial da Falha", pontuando-as de 0 a 10 em relação à Probabilidade de sua Ocorrência. Em seguida, a equipe deu sequência ao preenchimento do FMEA sobre os Controles atuais de prevenção e detecção, pontuando-os de 0 a 10 quanto à habilidade de Detecção desses controles. Essas informações são mostradas no Quadro 6. 
Quadro 6 - Causas potenciais da falha e controles atuais

\begin{tabular}{|c|c|c|c|c|c|}
\hline \multirow{2}{*}{ Modo de falha } & \multirow{2}{*}{ Causas Potenciais da Falha } & \multirow{2}{*}{ 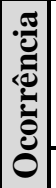 } & \multicolumn{2}{|c|}{ Controles Atuais } & \\
\hline & & & Prevenção & Detecção & \\
\hline $\begin{array}{c}\text { Peças com } \\
\text { Impurezas na } \\
\text { Região da Solda }\end{array}$ & $\begin{array}{l}\text { Os processos utilizados para limpeza das } \\
\text { peças não são eficazes nas regiões de solda }\end{array}$ & 8 & $\begin{array}{l}\text { Instrução de } \\
\text { Trabalho }\end{array}$ & $\begin{array}{l}\text { Visual Intra- } \\
\text { processo }\end{array}$ & 8 \\
\hline \multirow{3}{*}{$\begin{array}{l}\text { Peças com óleos e } \\
\text { graxas }\end{array}$} & $\begin{array}{l}\text { 1. A concentração de temperatura do } \\
\text { desengraxante não é respeitada, necessitando } \\
\text { de deixar mais tempo do que o especificado }\end{array}$ & 6 & \multirow{3}{*}{$\begin{array}{l}\text { Instrução de } \\
\text { Trabalho }\end{array}$} & $\begin{array}{l}\text { Visual Intra- } \\
\text { processo }\end{array}$ & 8 \\
\hline & $\begin{array}{l}\text { 2. A concentração do desengraxante não é } \\
\text { suficiente para realizar a limpeza }\end{array}$ & 6 & & $\begin{array}{l}\text { Análise de } \\
\text { laboratório } \\
\text { (diária) }\end{array}$ & 8 \\
\hline & $\begin{array}{l}\text { 3. A temperatura do desengraxante não é } \\
\text { suficiente para realizar a limpeza }\end{array}$ & 6 & & $\begin{array}{l}\text { Análise de } \\
\text { laboratório } \\
\text { (diária) }\end{array}$ & 8 \\
\hline
\end{tabular}

Por fim, a equipe calculou o índice de risco (NPR) através da multiplicação dos valores de Severidade, Ocorrência e Detecção. Depois de priorizados os modos de falha, foram propostas algumas ações, associadas a um responsável, incluindo o prazo de execução. Essas informações são mostradas no Quadro 7.

\begin{tabular}{|c|c|c|c|c|c|c|c|}
\hline \multirow{2}{*}{ Modo de Falha } & \multirow{2}{*}{ 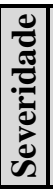 } & \multirow{2}{*}{ 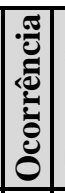 } & \multirow{2}{*}{ 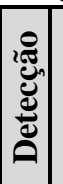 } & \multirow{2}{*}{ 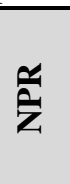 } & \multirow[t]{2}{*}{ Ações Recomendadas } & \multirow{2}{*}{ Responsável } & \multirow{2}{*}{$\begin{array}{l}\text { Prazo de } \\
\text { execução }\end{array}$} \\
\hline & & & & & & & \\
\hline $\begin{array}{l}\text { Peças com Impu- } \\
\text { rezas na } \\
\text { Região da Solda }\end{array}$ & 8 & 8 & 8 & 512 & $\begin{array}{l}\text { Verificar, através do DOE, se fazer desvio de } \\
\text { processo para utilização de Ácido Clorídrico } \\
\text { quente após desengraxante químico resolve o } \\
\text { problema }\end{array}$ & $\begin{array}{l}\text { Supervisor de } \\
\text { Produção }\end{array}$ & $15 /$ nov/10 \\
\hline \multirow{3}{*}{$\begin{array}{l}\text { Peças com óleos } \\
\text { e graxas }\end{array}$} & 8 & 6 & 8 & 384 & $\begin{array}{l}\text { Determinar a temperatura / concentração do } \\
\text { desengraxante para que o tempo de } 40 \mathrm{~min} \text {. } \\
\text { seja suficiente }\end{array}$ & $\begin{array}{l}\text { Equipe Seis } \\
\text { Sigma }\end{array}$ & 30/jan/11 \\
\hline & 8 & 6 & 8 & 384 & DOE para verificar a concentração ideal & $\begin{array}{l}\text { Treinadora / } \\
\text { Supervisor de } \\
\text { Produção }\end{array}$ & $15 /$ nov/10 \\
\hline & 8 & 6 & 8 & 384 & DOE para verificar a temperatura ideal & $\begin{array}{l}\text { Treinadora / } \\
\text { Supervisor de } \\
\text { Produção }\end{array}$ & $15 /$ nov/10 \\
\hline
\end{tabular}

Considerando a análise das 8 variáveis de entrada, resultantes da Matriz de Priorização, apenas as explicitadas previamente apresentaram altos índices de risco (NPR) e necessitaram de testes na linha de produção para verificar os parâmetros mais indicados para reduzir a ocorrência de falhas. Sendo assim, apenas estas foram explicitadas nesse artigo. No relatório completo, as NPRs variaram de 64 a 512 .

No primeiro caso, onde as etapas de desengraxe químico e eletrolítico não são suficientes para retirar as impurezas localizadas nas regiões de solda, a equipe decidiu realizar testes para verificar a eficiência da limpeza realizada com ácido clorídrico, com concentração de $40 \%$ a quente. Para a realização dos testes foi realizada uma modificação no processo usual onde, após a passagem pelo desengraxante químico, as peças seriam mergulhadas em um tanque com ácido clorídrico.

Os segundo e terceiro modos de falha priorizados estavam relacionados à temperatura e concentração do desengraxante químico. O operador de laboratório aprovava a produção desde que a concentração do banho estivesse entre $60 \mathrm{~g} / \mathrm{L}$ e $80 \mathrm{~g} / \mathrm{L}$, com temperaturas entre $60^{\circ} \mathrm{C}$ e $80^{\circ} \mathrm{C}$. Com o objetivo de determinar as condições ideais de temperatura e concentração do banho de desengraxante químico, 
a equipe decidiu que a melhor ação seria realizar um DOE, em conjunto com a modificação no processo (conforme descrito acima), e avaliar qual seria a situação que apresentaria o menor índice de peças reprovadas.

Os demais modos de falha, tratados no FMEA, tiveram como principais ações; o treinamento dos empregados quanto à importância da qualidade no processo, revisões dos planos de manutenção dos equipamentos, implantação de verificações no decorrer do processo e o aumento na frequência das análises laboratoriais.

\subsection{Fase implantar melhorias}

Com base nos modos de falha priorizados no FMEA e nas três principais ações a serem implantadas, a equipe definiu os valores que seriam testados através do DOE, ou seja:

- X1: Temperatura do Desengraxante: 60,70 e $80^{\circ} \mathrm{C}$

- X2: Concentração do Desengraxante: 60,70 e $80 \mathrm{~g} / \mathrm{L}$

- $\quad$ X3: Utilização de Ácido Clorídrico quente, com ou sem alteração do processo usual.

Os valores de temperatura e concentração foram assim definidos por serem os limites aceitáveis durante a análise de laboratório para a aprovação. Com o objetivo de testar a eficácia da utilização do ácido clorídrico a quente, todas as combinações foram realizadas, com e sem a utilização do ácido. Para verificar a eficácia de todas as ações tomadas, definiu-se como indicador de desempenho o índice de peças reprovadas, expressas em forma de percentagem. Assim, definiu-se como melhor situação aquela que apresentasse o menor índice de retrabalho no período.

A Tabela 6 apresenta, para cada experimento, as variáveis de entrada utilizadas e, como saídas, as seguintes variáveis: o número de peças produzidas na condição do teste específico, a quantidade de peças aprovadas, a quantidade de peças reprovadas e o índice de retrabalho (razão entre peças reprovadas e peças produzidas). Os 18 testes realizados foram suficiente para simular todas as combinações entre as variáveis descritas previamente.

Tabela 6 - Resultados do projeto de experimentos

\begin{tabular}{|c|c|c|c|c|c|c|c|}
\hline \multicolumn{4}{|c|}{ Entradas } & \multicolumn{4}{|c|}{ Saídas } \\
\hline \multirow[t]{2}{*}{ N. } & \multirow[t]{2}{*}{$\begin{array}{l}\text { Temperatura do } \\
\text { Desengraxante }\end{array}$} & \multirow[t]{2}{*}{$\begin{array}{c}\text { Concentração do } \\
\text { Desengraxante }\end{array}$} & \multirow[t]{2}{*}{$\begin{array}{l}\text { Utiliza } \\
\text { Ácido? }\end{array}$} & \multicolumn{4}{|c|}{ Índice de Retrabalho } \\
\hline & & & & Produzidas & Aprovadas & Reprovadas & $\%$ \\
\hline 1 & 60 & 60 & SIM & 243 & 215 & 28 & 11,5 \\
\hline 2 & 60 & 60 & NÃO & 178 & 142 & 36 & 20,2 \\
\hline 3 & 60 & 70 & SIM & 315 & 287 & 28 & 8,9 \\
\hline 4 & 60 & 70 & NÃO & 246 & 205 & 41 & 16,7 \\
\hline 5 & 60 & 80 & SIM & 254 & 227 & 27 & 10,6 \\
\hline 6 & 60 & 80 & NÃO & 213 & 175 & 38 & 17,8 \\
\hline 7 & 70 & 60 & SIM & 505 & 448 & 57 & 11,3 \\
\hline 8 & 70 & 60 & NÃO & 393 & 321 & 72 & 18,3 \\
\hline 9 & 70 & 70 & SIM & 398 & 370 & 28 & $\begin{array}{l}7,0 \\
\end{array}$ \\
\hline 10 & 70 & 70 & NÃO & 330 & 284 & 46 & 13,9 \\
\hline 11 & 70 & 80 & SIM & 297 & 268 & 29 & \begin{tabular}{|c|}
9,8 \\
\end{tabular} \\
\hline 12 & 70 & 80 & NÃO & 325 & 272 & 53 & 16,3 \\
\hline 13 & 80 & 60 & SIM & 230 & 205 & 25 & 10,9 \\
\hline 14 & 80 & 60 & NÃO & 212 & 183 & 29 & 13,7 \\
\hline 15 & 80 & 70 & SIM & 322 & 308 & 14 & $\overline{4,3}$ \\
\hline 16 & 80 & 70 & NÃO & 364 & 325 & 39 & 10,7 \\
\hline 17 & 80 & 80 & SIM & 300 & 273 & 27 & 9,90 \\
\hline 18 & 80 & 80 & NÃO & 220 & 189 & 31 & 14,1 \\
\hline
\end{tabular}

Inicialmente, pode-se observar que os experimentos 3, 9, 11, 15 e 17 apresentam índices de retrabalho inferiores a 10\%, conforme o objetivo do projeto. Em uma análise mais detalhada, é possível observar que os índices de reprovação mais baixos, para quaisquer temperaturas, foram obtidos utilizando-se a concentração de $70 \mathrm{~g} / \mathrm{L}$ de desengraxante. Além disso, em todas as condições, a utilização de ácido clorídrico reduziu significativamente o índice de retrabalho. Fixando-se a concentração em 
$70 \mathrm{~g} / \mathrm{L}$ e utilizando a modificação no processo, descrita anteriormente, observa-se que quanto maior a temperatura do banho, menor o índice de retrabalho, chegando a 4,3\% para a condição de temperatura máxima, ou seja, $80^{\circ} \mathrm{C}$.

Com o objetivo de validar os resultados obtidos, a equipe decidiu realizar, pelo período de um mês, testes confirmatórios a partir da melhor condição obtida através do DOE, ou seja: Temperatura de $80^{\circ} \mathrm{C}$; Concentração de $70 \mathrm{~g} / \mathrm{L}$ e modificando o processo com a utilização do ácido clorídrico. A Tabela 7 mostra os resultados desses testes, confirmando os resultados obtidos com o DOE.

Tabela 7 - Confirmação dos resultados obtidos com o DOE

\begin{tabular}{|c|c|c|c|c|c|}
\hline Data & Produzidas & Reprovadas & $\%$ & DPMO & Nível Sigma \\
\hline 03/jan/11 & 123 & 6 & 4,9 & 48780 & 3 \\
\hline 04/jan/11 & 300 & 12 & 4,0 & 40000 & 3 \\
\hline 05/jan/11 & 287 & 6 & 2,1 & 20906 & 3 \\
\hline 06/jan/11 & 182 & 6 & 3,3 & 32967 & 3 \\
\hline $07 / \mathrm{jan} / 11$ & 170 & 11 & 6,5 & 64706 & 3 \\
\hline 10/jan/11 & 215 & 8 & 3,7 & 37209 & 3 \\
\hline 11/jan/11 & 97 & 2 & 2,1 & 20619 & 3 \\
\hline 12/jan/11 & 147 & 6 & 4,1 & 40816 & 3 \\
\hline 13/jan/11 & 123 & 6 & 4,9 & 48780 & 3 \\
\hline 14/jan/11 & 177 & 11 & 6,2 & 62147 & 3 \\
\hline 15/jan/11 & 419 & 10 & 2,4 & 23866 & 3 \\
\hline 16/jan/11 & 287 & 6 & 2,1 & 20906 & 3 \\
\hline 17/jan/11 & 124 & 4 & 3,2 & 32258 & 3 \\
\hline 18/jan/11 & 312 & 14 & 4,5 & 44872 & 3 \\
\hline 19/jan/11 & 235 & 14 & 6,0 & 59574 & 3 \\
\hline 20/jan/11 & 221 & 8 & 3,6 & 36199 & 3 \\
\hline 21/jan/11 & 298 & 10 & 3,4 & 33557 & 3 \\
\hline 24/jan/11 & 243 & 12 & 4,9 & 49383 & 3 \\
\hline 25/jan/11 & 175 & 10 & 5,7 & 57143 & 3 \\
\hline 26/jan/11 & 134 & 8 & 6,0 & 59701 & 3 \\
\hline \multicolumn{5}{|c|}{ Media Sigma } & 3 \\
\hline
\end{tabular}

Conforme apresentado, o objetivo do projeto Seis Sigma nesta pequena empresa pôde ser concluído, visto que nos 20 testes o índice de retrabalho não ultrapassou o limite de $10 \%$. Com isso, o processo mais crítico da empresa, pelo montante de retrabalhos e atrasos, conseguiu evoluir do Nível Sigma 2, para o Nível Sigma 3, impactando em economias significativas para a empresa, sem a necessidade de altos investimentos.

\subsection{Fase controlar}

Na última fase do DMAIC a equipe Seis Sigma elaborou um Plano de Controle para garantir que, depois de concluído o projeto, os responsáveis pudessem controlar as variáveis pertinentes com a frequência necessária, considerando as ações a serem tomadas, caso algum parâmetro saísse do especificado. Dentre os controles abordados neste Plano estão a verificação diária da concentração e temperatura do desengraxante, com os valores estipulados pelo DOE, e o controle dos tempos de banho. Além do Plano de Controle, as Cartas de Controle foram alocadas na linha de produção e, diariamente, um analista da qualidade atualiza os dados com a percentagem de retrabalho da produção. A Figura 12 mostra a carta de controle com os dados do mês de Janeiro de 2011, quando foram realizados os testes para confirmar os dados previamente obtidos. 


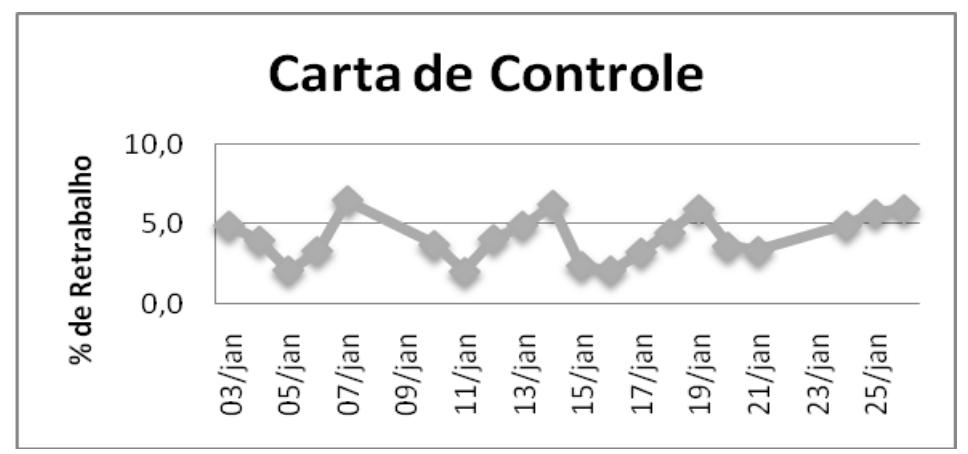

Figura 12 - Carta de controle

Ao final do projeto constatou-se que, apesar de a equipe ter estipulado como meta inicial, melhorar o processo de Zincagem para que houvesse no máximo $10 \%$ de reprovação das peças finais, após esse trabalho obteve-se no máximo 6,5\% de reprovação até o dia 7/01/11. A empresa entende que níveis de reprovação inferiores a $10 \%$ são aceitáveis devido à instabilidade do processo químico. A média mensal de Janeiro de 2011 foi de $4 \%$ de reprovação, enquanto que antes da aplicação do Seis Sigma, entre março e agosto de 2010, o índice de reprovação variou de $14,7 \%$ a 36,1\%. Ou seja, esta aplicação de Seis Sigma contribuiu com a empresa, superando a meta inicial.

\section{Considerações finais}

A aplicação do Seis Sigma nas MPMEs é um tema emergente entre os acadêmicos nos últimos anos, considerando que essa metodologia foi criada originalmente para as grandes empresas. Ainda existem poucos registros de sucesso do Seis Sigma nesse perfil de empresa, considerando suas limitações relacionadas aos recursos financeiros e humanos. Apesar disso, o perfil dessas empresas apresenta fatores contributivos para a aplicação do 6 Sigma como, por exemplo, a agilidade no processo decisório e o suporte e comprometimento de seus gestores. Sendo assim, esse artigo mostra uma aplicação prática do Seis Sigma através do método DMAIC em uma pequena empresa que realiza tratamento superficial por zincagem, visando mostrar a aplicabilidade do Seis Sigma e o seu impacto positivo para a pequena empresa. Neste caso prático, apenas alguns recursos recomendados na aplicação do Seis Sigma são utilizados, visando simplificar e reduzir os custos dos procedimentos. Entre eles estão: a formação da equipe Seis Sigma, a definição do processo mais crítico, a elaboração da carta de projeto, a definição da missão, o mapeamento do processo, a priorização de variáveis através da utilização da Matriz de Priorização, a priorização das causas e ações de melhoria com a utilização do FMEA de processo, a realização de testes com o DOE e a elaboração do Plano e Cartas de Controle.

A análise mostrou que as principais causas dos problemas estavam relacionadas à temperatura e à concentração do desengraxante químico, que não eram bem definidas, e o fato de as etapas de limpeza não serem suficientes para retirar as impurezas da região de solda. Sendo assim, foram realizados 20 testes laboratoriais, visando determinar as melhores condições de temperatura e concentração, além de validar a eficácia de uma alteração no processo inicial, o que incluía mais uma etapa de limpeza. A partir desses testes, foi possível determinar que o melhor desempenho do processo ocorria com a temperatura do desengraxante a $80^{\circ} \mathrm{C}$ e concentração de $70 \mathrm{~g} / \mathrm{L}$, considerando a alteração do processo usual. Constatou-se que a aplicação do Seis Sigma nesta pequena empresa foi viável e benéfica, melhorando significativamente o desempenho do processo delimitado para o estudo; afinal, a redução da média do índice de retrabalho passou de $23 \%$ para $4 \%$. Também houveram ganhos qualitativos como a transferência de conhecimento para os membros da equipe quanto às técnicas de qualidade e o estabelecimento de uma cultura para monitorar e reduzir defeitos através da mensuração e controle dos mesmos.

Dentre os principais obstáculos encontrados durante a aplicação da metodologia pode-se citar a dificuldade em reunir a equipe Seis Sigma nos horários programados, devido às atividades exercidas dentro da empresa. Também houve restrições quanto às ações serem de baixo custo, respeitando os baixos recursos provenientes de uma típica empresa de pequeno porte. Para trabalhos futuros, sugere- 
se a aplicação da metodologia Seis Sigma em micro empresas, visando constatar a sua viabilidade e eficácia.

\section{Referências}

ANDRIETTA, J. M.; MIGUEL, P. A. C. A Importância do Método Seis Sigma na Gestão da Qualidade Analisada sob uma Abordagem Teórica. Ciência \&Tecnologia, v.11, n.20, p.91-98, Dez. 2002.

ANDRIETTA, J. M.; MIGUEL, P. A. C. Aplicação do Programa Seis Sigma no Brasil: resultados de um levantamento tipo survey exploratório-descritivo e perspectivas para pesquisas futuras. Gestão \& Produção, v.14, n.2, p.203-219, Ago. 2007.

ANTONY, J. Can Six Sigma be effectively implemented in SMEs? International Journal of Productivity and Performance Management, v.57, n.5, p.420-423, 2008.

ANTONY, J.; KUMAR, M.; MADU, C. N. Six Sigma in Small - and Medium - sized UK manufacturing enterprises: some empirical observations. International Journal of Quality \& Reliability Management, Bradford, v.22, n.8/9, p.860-874, 2005.

ARIENTE, M. et al. Processo de Mudança Organizacional: estudo de caso do Seis Sigma. Revista da FAE, v.8, n.1, p.81-92, Jun. 2005.

BOARIN P., S. H.; CARVALHO, M. M.; LEE HOO, L.; RIGAZZ, S. Programas de Melhoria da Qualidade no Setor Bancário: Uma Análise Comparativa do Cenário Brasileiro e Português. Produto \& Produção, v.10, n.3, p. 77-85, Out. 2009.

BRUE, G. Six Sigma for small business. Entrepreneur Press, 2006.

CARVAlHO, M. M. de; HO, L. L.; PINTO, S. H. B. Difusão do programa Seis Sigma no Brasil. Produção, v.17, n.3, p.486-501, 2007.

CARVALHO, M. M.; PALADINI, E. P. Gestão da qualidade: teoria e casos. Rio de Janeiro: Campus, 2005.

CLETO, M. G.; QUINTEIRO, L. Gestão de projetos através do DMAIC: um estudo de caso na indústria automotiva. Revista Produção Online, v.11, p. 210-239, 2011.

CUNICO, M. W.; CUNICO, M. M.; MIGUEL, O. G.; ZAWADZKI, S. F.; PERALTA-ZAMORA, P.; VOLPATO, N. Planejamento fatorial: uma ferramenta estatística valiosa para a definição de parâmetros experimentais empregados na pesquisa científica. Revista Visão Acadêmica, v.9, n.1, 2008.

DUARTE JUNIOR, N. S. F.; RAMOS, A. W. Aspectos complexos da implantação de metodologias da qualidade. In: Simpósio de Engenharia de Produção (SIMPEP), Bauru, 2006.

EINSET, E.; MARZANO, J. Six Sigma Demystified. Tooling \& Production, v.13, 2002.

ESTORILIO, C.; POSSO, R. The reduction of irregularities in the use of process FMEA, International Journal of Quality \& Reliability Management, v.27, n.6, p.721-733, 2010.

GASPERINI, V. Pequenas lojas formam cooperativas para fazer frente a grandes redes. Revenda Construção, n.121, Ago. 2000.

HARRY, M. J.; CRAWFORD, J. D. Six Sigma for the little guy. Mechanical Engineering. v.126, n.11, p.8-10, Nov. 2004. 
HENDERSON, K. M.; EVANS, J. R. Successful implementation of Six Sigma: benchmarking General Electric company. Benchmarking: an International Journal, v.7, n.4, p.260-282, 2000.

KAUSHIK, P.; KHANDUJA, D.; MITTAL, K.; JAGLAN, P. A case study; Application of Six Sigma methodology in a small and medium-sized manufacturing enterprise. TQM Journal. v.24, n.1, p. 4-16, 2012.

KLEFSJÖ, B.; WIKLUND, N.; EDEGMAN, R. L. Six Sigma seen as a methodology for total quality management. Measuring Business Excellence, v.5, 2001.

KURATKO, D. F.; GOODALE J. C.; HORNSBY, J. S. Quality practices for a competitive advantage in smaller firms. Journal of Small Business Management, Morgantown, v.39, n.4, p.293-311, Oct. 2001.

BOER, S. D.; ANDHARIA, R., HARTEVELD, M.; HO, L. C.; MUSTO, P. L.; PRICKEL, S. Six Sigma for IT Management. Van Haren Publishing, 2007. 161p.

MACHADO, M. P. P. Uma Análise Sobre a Estratégia de Diferenciação no Setor de Cosméticos: O Caso Natura. 2006. Trabalho de Conclusão de Curso (Graduação) - Curso Superior de Ciências Econômicas. Universidade Federal de Santa Catarina, Florianópolis, 2006.

MAGALHÃES, S. S.; FIGUEIREDO, V. F. Fatores Críticos para Implementação de Seis Sigma em Pequenas e Médias Empresas da Cadeia Produtiva de Petróleo e Gás. In: XXVII Encontro Nacional de Engenharia de Produção, 2007. Anais. Foz do Iguaçu, 2007.

MAST, J.; LOKKERBOL, J. An analysis of the Six Sigma DMAIC method from the perspective of problem solving. International Journal Production Economics. v.139, n.2, p. 604-614, 2012.

MAS. Manual de análise de sistemas de medição. $4^{\text {a }}$ Edição, Jun. 2010.

MUNRO, R. A. Linking six Sigma with QS-9000. Quality Progress, Milwaukee, v.33, n.5, p.47-53, May. 2000.

OLIVEIRA, O. J. Pequena Empresa no Brasil: Um Estudo de suas Características e Perspectivas. Revista Integração, Ano XII, n.44, p.5-15, Mar. 2006.

PANDE, P. S.; NEUMAN R. P.; ROLAND, C. The Six Sigma Way: How GE, Motorola, and other Top Companies are Honing their Performance. India: McGraw-Hill Education, 2003

PANDE, P. S.; NEUMAN R. P.; ROLAND, C. Estratégia Seis Sigma: como a GE, a Motorola e outras grandes empresas estão aguçando seu desempenho. Rio de Janeiro: Qualitymark, 2001.

PINTO, Silvia Helena Boarin; CARVALHO, Marly Monteiro de; HO, Linda Lee: Programas de Qualidade: Um Survey em Empresas de Grande Porte no Brasil. Revista Gestão e Produção, São Paulo, v. 13, 2006.

PYZDEK, T. The Six Sigma Handbook. New York: McGraw-Hill, 2003.

RATH ; STRONG. Six Sigma Pocket Guide, 2. ed. Lexington, 2001, 192 p. ISBN 0974632872.

RODRIGUES, J.; WERNE, L. Seis Sigma: características do programa em onze empresas situadas na região metropolitana de Porto Alegre. Revista Produção Online. v.12, n.1, p.2-22, 2012.

ROTONDARO, R. G. (Coord.). Seis Sigma: estratégia gerencial para a melhoria de processos, produtos e serviços. São Paulo: Atlas, 2002. 
RUTHES, S.; CERETTA, P. S.; SONZA, I. B. Seis Sigma: Melhoria da qualidade através da redução da variabilidade. Revista Gestão Industrial, v.2, n.2, p.181-199, 2006.

SANTOS, A. B.; MARTINS, M. F. Contribuições do Seis Sigma: estudos de caso em multinacionais. Revista Produção, v.20, n.1, Mar. 2010.

SATOLO, E. G.; ANDRIETTA, J. M.; MIGUEL, P. A. C., CALARGE, F. A. Análise da utilização de técnicas e ferramentas no programa Seis Sigma a partir de um levantamento tipo survey. Revista Produção, v.19, n.2, 2009.

SEBRAE/SP. Conhecendo a pequena empresa. São Paulo: SEBRAESP, 2005. Disponível em: <http://www.sebraesp.com.br/Principal/Conhecendo\%20a\%20MPE/> Acesso em: 08 de maio de 2006.

TJAHJONO, B.; BALL, P.; VITANOV, V.; SCORZAFAVE, C.; NOGUEIRA, J.; CALLEJA, J.; MINGUET, M.; NARASIMHA, L.; RIVAS, A.; SRIVASTAVA, A.; SRIVASTAVA, S.; YADAV, A. Six Sigma: a literature review. International Journal of Lean Six Sigma. v.1, n.3, p.216-233, 2010.

TONINI, A. C.; CARVALHO, M. M.; SPINOLA, M. M. Contribuição dos modelos de qualidade e maturidade na melhoria dos processos de software. Produção On-Line, v.18, n. 2, p.275-286, 2008.

VIEIRA, D. R.; ALMEIDA, F. L. Projeto de desenvolvimento de novos produtos: o caso da Racco Cosméticos. Revista Mundo PM, ano 4, n.22, p.66-74, Ago. 2008.

WELCH, J. J. Definitivo: Segredos do Executivo do Século. Rio de Janeiro: Campus, 2001.

WESSEL, G.; BURCHER P. Six Sigma for small and medium-sized enterprises. The TQM Magazine, Bedford, v.16, n.4, p.264-272, 2004. 